\title{
Exploring the Efficacy of Anti-amyloid- $\beta$ Therapeutics in Treating Alzheimer Disease
}

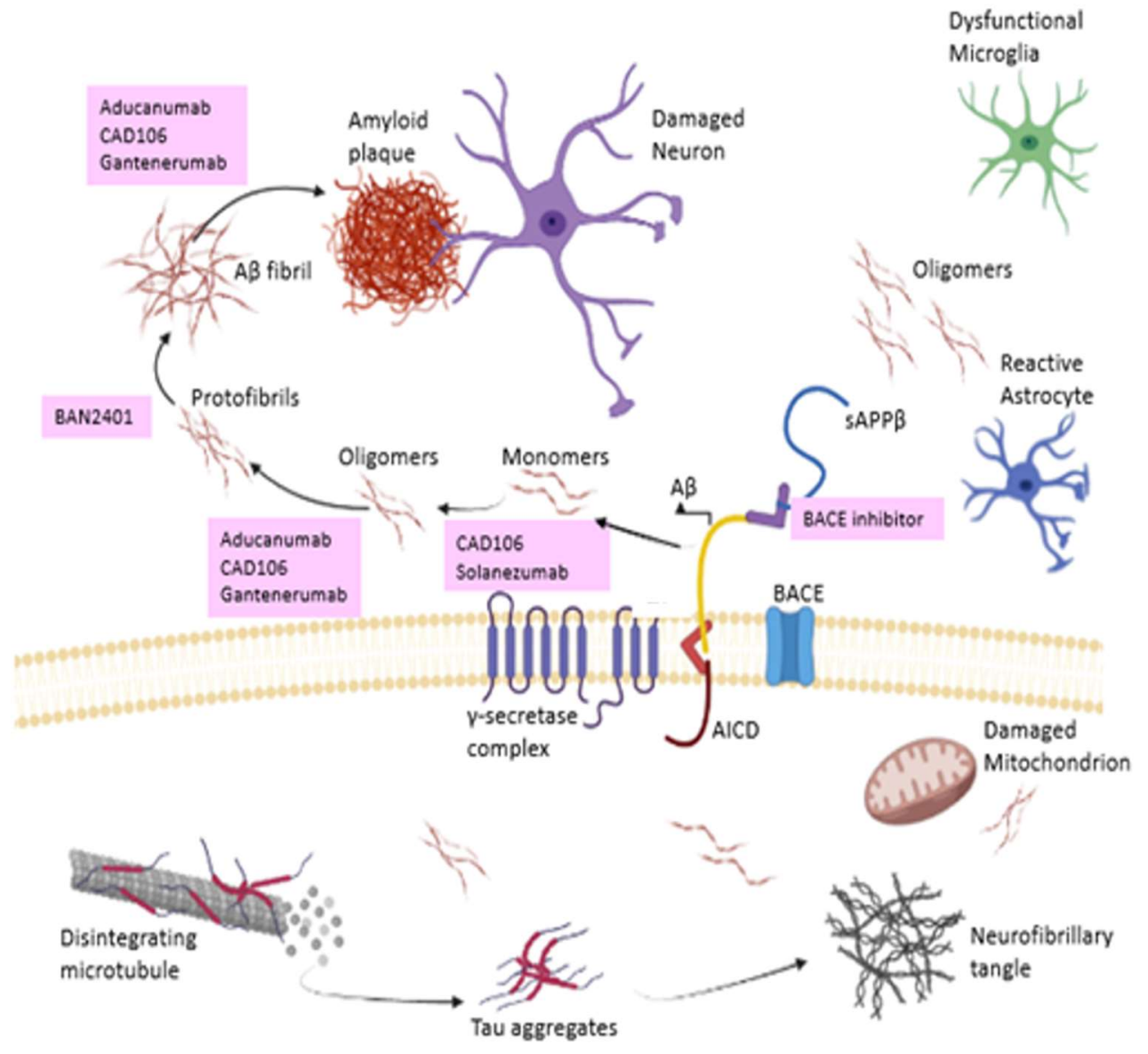

Author: Ciara Downey

https://doi.org/10.51892/ysm.1.202201

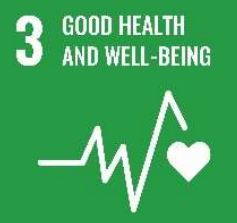




\title{
Exploring the Efficacy of Anti-amyloid- $\beta$ Therapeutics in Treating Alzheimer Disease
}

\author{
Ciara Downey ${ }^{1}$
}

${ }^{1}$ Biochemistry, National University of Ireland, Galway

\section{ABSTRACT}

Alzheimer Disease (AD) is the most prevalent cause of dementia, characterized by initial memory impairment and progressive cognitive decline. The exact cause of $A D$ is not yet completely understood. However, the presence of neurotoxic amyloid-beta $(A \beta)$ peptides in the brain is often cited as the main causative agent in $A D$ pathogenesis. In accordance with the amyloid hypothesis, $A \beta$ accumulation initially occurs 15-20 years prior to the development of clinical symptoms. Current therapies focus on the prodromal and preclinical stages of $A D$ due to past treatment failures involving patients with mild to moderate $A D$. Passive immunization via exogenous monoclonal antibodies (mAbs) administration has emerged as a promising anti-A $\beta$ treatment in $A D$. This is reinforced by the recent approval of the mAb, aducanumab. mAbs have differential selectivity in their epitopes, each recognising different conformations of $A \beta$. In this way, various $A \beta$ accumulative species can be targeted. mAbs directed against $A \beta$ oligomers, the most neurotoxic species, are producing encouraging clinical results. Through understanding the process by which mAbs target the amyloid cascade, therapeutics could be developed to clear $A \beta$, prevent its aggregation, or reduce its production. This review examines the clinical efficacy evidence from previous clinical trials with anti-A $\beta$ therapeutics, in particular, the mAbs. Future therapies are expected to involve a combined-targeted approach to the multiple mechanisms of the amyloid cascade in a particular stage or disease phenotype. Additional studies of presymptomatic $A D$ will likely join ongoing prevention trials, in which mAbs will continue to serve as the focal point.

Keywords: clinical trials, active immunization, presymptomatic, vaccine, amyloid hypothesis, monoclonal antibodies, passive immunization, amyloid-beta, Alzheimer Disease

(c) 2022 The Author(s). Licensee Youth STEM 2030, Glasgow, Scotland. This article is an open access article distributed under the terms and conditions of the Creative Commons Attribution 4.0 International License (CC BY) license (http://creativecommons.org/licenses/by/4.0/). 


\section{INTRODUCTION}

$A D$ is one of the biggest biomedical care challenges of this century. Only four decades ago, AD was virtually unknown to the public. $A$ rise in the prevalence of $A D$ is attributed to an aging worldwide population, with approximately 40 million individual $A D$ cases. This figure is expected to double every 20 years until 2050 [1, 2]. Therefore, the provision of effective $A D$ treatments is urgent [3]. Since 2003, no new therapeutics that slow or stop the progression of $A D$ clinical decline have been approved by the American Food and Drug Administration (FDA) [4]. That is until June 7th, 2021, when the FDA granted the mAb aducanumab accelerated approval [5]. For the last 17 years, only symptomatic treatments were available [4]. However, aducanumab marks the first $A D$ treatment associated with slowing the rate of $A D$ progression [6]. $A D$ is accountable for up to $70 \%$ of all cases of dementia [7]. Dementia is associated with the age-linked degeneration of the brain's neurocognitive domains, affecting a person's behaviour, thinking, and memory. These effects can occur as initial symptoms of $A D$, depicted as preclinical $A D$, and can affect an individual's cognitive function a decade or more before overt brain dysfunction [8].

The cardinal features of $A D$, namely amyloid plaques and neurofibrillary tangles (NFTs), have been recognised for over a hundred years, having first been described by Alois Alzheimer, the Bavarian psychiatrist that $A D$ was named after [9]. Alzheimer attempted to correlate the clinical symptoms of his patient, Auguste D., to the pathological features he observed in her autopsied brain, specifically nerve cells with dense fibril bundles (NFTs) and 'miliary foci' (amyloid plaques) [10]. Decades later in 1984, George Glenner shifted the focus from $A D$ pathology to genetics through his and Caine Wong's prediction of an
AD gene located on chromosome 21. Glenner and Wong derived and analysed cerebrovascular amyloid from patients with Down Syndrome (trisomy 21) and reported the amino acid sequence of $A \beta$ [11]. It was this study that initiated AD's 'amyloid hypothesis,' which was further backed up by three separate studies conducted independently in 1991 [1214]. The amyloid hypothesis describes how $A \beta$ protein accumulation is the initial event in the $A D$ process $[7,15]$. It is the production of $A \beta$ in the brain that leads to the development of $A D$ clinical syndrome [2]

Amyloid plaques are located extracellularly between neurons and consist of fibrils containing $A \beta$ peptides. NFTs are intracellular and consist of tau, a hyperphosphorylated protein. Both these lesions represent the two neuropathological hallmarks of $A D$ that present research is currently focused on $[7,16,17]$. To this day, the presence of $A \beta$ and NFTs are still required for $A D$ pathological diagnosis [18]. The primary amino acid sequence of $A \beta$ was first characterized and purified from extracellular amyloid plaques in 1984 [15]. A $\beta$ is composed of a group of peptides ranging from 37 to 49 amino acid residues in size. Various structural approaches, such as distance geometry, X-ray crystallography, and nuclear magnetic resonance, highlighted the structural conversion from $A \beta$ monomers to oligomers, protofibrils, fibrils, to amyloid plaque deposition. This conversion involves a quick structural state transition, in which the loosely aggregated strands are associated into helical and $\beta$-sheet structures [19]. As the oligomeric state is more transient, its structural characterization is more complicated than that of amyloid fibrils [20]. New insights into aggregation and structural pathways may assist in uncovering the mechanisms of amyloid pathogenesis in neurodegenerative diseases. This could ultimately lead to new 
therapeutic strategies aimed at preventing the formation of neurotoxic $A \beta$ aggregates [19].

$A \beta$ is a family member of amyloid polypeptides, and following its improper folding, it can inappropriately interact with certain cell types to invoke neurodegenerative diseases, such as Huntington's, Parkinson's, prion disease, and $A D$ [21]. In $A D$, neurons throughout the brain can become injured and die, causing neuron connections to disassemble and the shrinkage of certain brain regions. In the final AD stages, this process is known as brain atrophy. At an anatomical level $A D$ is defined by brain atrophy, which involves neural loss. To some degree, this atrophy and subsequent brain shrinkage is seen in cognitively healthy aging individuals. However, in individuals who suffer from mild cognitive impairment $(\mathrm{MCl})$, there is an acceleration of this atrophy. This atrophy acceleration is increased further in individuals who progress from $\mathrm{MCl}$ to $\mathrm{AD}$ [22]. Anomalous neural activity, loss of neurons and synapses, and degeneration of specific populations in the neuronal ensemble are associated with $A D$ patients' cognitive decline [3]. Structural Magnetic Resonance Imaging (MRI) is used to assess brain atrophy, in particular, the hippocampus, and this has been noted as a valid $A D$ biomarker through post-mortem histology [23, 24].

The two main types of $A D$ are late-onset (LOAD), also known as sporadic $A D$, and earlyonset (EOAD) or dominant familial $A D$. The apolipoprotein E (APOE ع4) allele is linked to abnormal $A \beta$ accumulation and has the strongest genetic risk factor link to LOAD [17]. EOAD occurs in approximately $5-10 \%$ of all AD cases and arises from mutations in either the presenilin 1 gene (PSEN-1), the presenilin 2 gene (PSEN-2), or the amyloid precursor protein (APP) encoding gene [25]. These gene products influence the formation of $A \beta$ [26]. The $A \beta$ peptide is generated through the cleavage of APP by $\gamma$-secretase and $\beta$ secretase. Factors such as alterations in proteolysis, protein folding machinery, amino acid sequence mutations, and protein hydrophobicity can cause $A \beta$ aggregation, which forms the amyloid plaques [27]. Individuals with trisomy 21 have an extra APP gene copy, which results in an increased risk of $A D$ development later in life due to increased amyloid production [7]. From certain EOAD forms, it was discovered that mutations in the APP gene lead to the enhanced production of $A \beta$, strongly suggesting that amyloidogenic $A \beta$ leads to $A D$ [28]. Protective mutations that reduce cleavage of the APP have been described, which lower the risk of $A D$ development [26]. Through understanding the factors that lead to $A D$ pathogenesis, it becomes vital to address the mechanisms of disease, its diagnosis, and the development of effective anti-A $\beta$ therapeutics against it.

The diagnosis of $A D$ is based upon an individual's medical history and clinical findings, at times verified by brain imaging, such as Positron Emission Tomography (PET) and MRI. Excluding aducanumab, current therapies target symptoms and do not affect $A D$ progression [17]. Only four acetylcholinesterase (AChE) inhibitors and one type of an N-methyl-D-aspartate receptor antagonist have been FDA approved for AD treatment [4]. In the past 18 years, many drugs, including BACE1, $\gamma$ - and $\beta$-secretase inhibitors have been developed to antagonize the aggregation of $A \beta$, decrease its production, or clear the increased levels of $A \beta$ in the brain, with little to no success (Table 1) [16]. Currently, the most comprehensive anti-A $\beta$ approaches are active and passive immunotherapy [29]. Active immunization stimulates the clearance of $A \beta$ due to an immunological response elicited by administering an $A \beta$ antigen [16]. However, immunologically-based long term adverse 
reactions and irregular or absent immune responses may occur, particularly in elderly individuals [29].

As the initiation of $A \beta$ accumulation occurs 1520 years before clinical symptoms, drugs such as the mAbs are currently in phase III clinical trials in patients with asymptomatic or preclinical stages of $A D$ and patients with a high risk of $A D$ [17]. The approval of aducanumab is conditional and in accordance with prescribing information from the US FDA, only patients with $\mathrm{MCl}$ or early $A D$ can be treated using this mAb. This correlates with the populations treated in clinical trials. Consequently, there is no effectiveness or safety data on the initiation of treatment at a later stage of disease progression. Aducanumab's approved status may be contingent upon further clinical benefit results in confirmatory trials [30]. mAbs are produced by cloning immune cells from unique parent cells. These antibodies have a monovalent affinity as they bind to the same epitope.

Either humanized or fully human mAbs are used in treating AD. Humanized antibodies are produced from protein modifications in nonhuman species that have sequence similarity to the naturally occurring human variants. The fully human mAbs can avoid some of the side effects experienced by humanized antibodies as they are derived from phage display or transgenic mice [31]. Amyloid-related imaging abnormalities (ARIA) are commonly experienced through passive immunization with mAbs [26]. In passive immunization, the toxic $A \beta$ species are cleared directly, with complement activation or through microglia, which are a specialised subtype of macrophages (Fig. 1) [31]. In comparison to active immunization, the adverse events associated with passive immunization can be controlled through stalling treatment. Also, antibody titers are kept consistent [29]. Reasons for past clinical failures associated with mAbs include late intervention, poor-target engagement, and inappropriate trial patient selection $[16,17]$. These clinical failures could potentially undermine further development of anti-A $\beta$ therapeutics. However, current ongoing trials will hopefully highlight this critical issue [32].

\section{$A \beta$ and the Amyloid Hypothesis}

The association with inherited EOAD resulted in the formation of the amyloid hypothesis [26]. Proteolytic processing is a type of posttranslational modification (PTM) in which the target protein's activity is modified from the cleavage of a protease on one or more of its bonds. Secretase enzymes function in the alternative proteolytic processing of APP (reviewed in [33]). It is the proteolytic processing of the ubiquitous glycoprotein APP that generates the $A \beta$ peptide [34]. The metabolism of APP is usually carried out by an extracellular protease $\alpha$-secretase and an intramembrane protease $\mathrm{y}$-secretase, creating a soluble protein that can be broken down to aid in neuron repair [2]. This is so-called the non-amyloidogenic pathway, and it co-exists with the pathologic (abnormal) amyloidogenic pathway in which the toxic $A \beta$ peptide is formed [34]. The sequential cleavage of the APP with $\gamma$-secretase and $\beta$-secretase, also known as $\beta$-site APP cleaving enzyme 1 (BACE1), gives rise to $A \beta[1,2]$. Cleavage with BACE1 generates an $\mathrm{N}$-terminal fragment, called the soluble amyloid precursor protein- $\beta$ (sAPP $\beta$ ), and a membrane-bound fragment C99. C99 in turn is cleaved by a 4-protein enzymatic complex within the membrane, known as the $\gamma$-secretase complex. $A \beta$ is released from the cleavage of $\gamma$-secretase to a peptide named the amyloid intracellular domain [16]. This $A \beta$ tends to have 'sticky' monomers that clump together to produce extracellular $A \beta$ fibrils highly resistant to proteolysis. $A \beta$ aggregation forms oligomers, 
protofibrils, $A \beta$ fibrils, and eventually $A \beta$ plaques (Fig. 1).

The molecular mechanism that drives $A \beta$ aggregation involves the formation of different soluble oligomeric intermediates of various structures and sizes. These oligomeric species play a key role in the amyloid cascade that ultimately develops into $A D$ through various neurotoxic events, such as mitochondrial damage, cell membrane permeabilization, inflammation, oxidative stress, and calcium dysregulation [35]. It is thought that the direct binding of $A \beta$ oligomers to specific neuron receptors disrupts the typical signalling cascade [31]. The most recognised variants of $A \beta$ are $A \beta 42$ and $A \beta 40$, comprising of 42 , and 40 amino acid residues, respectively. $A \beta 42$ is the main isoform in amyloid plaques and has the most neurotoxic form [36]. Therefore, it is no surprise that $A \beta 42$ production reduction is one of the three therapeutic strategies used in AD treatment. The other two mechanisms of action (MOAs) employed in anti-amyloid disease-modifying treatments are Prevention of $A \beta$ aggregation, and $A \beta$ clearance [2]. Fig. 1 shows the anti-A $\beta$ drugs that are currently in clinical trials for $A D$ treatment.

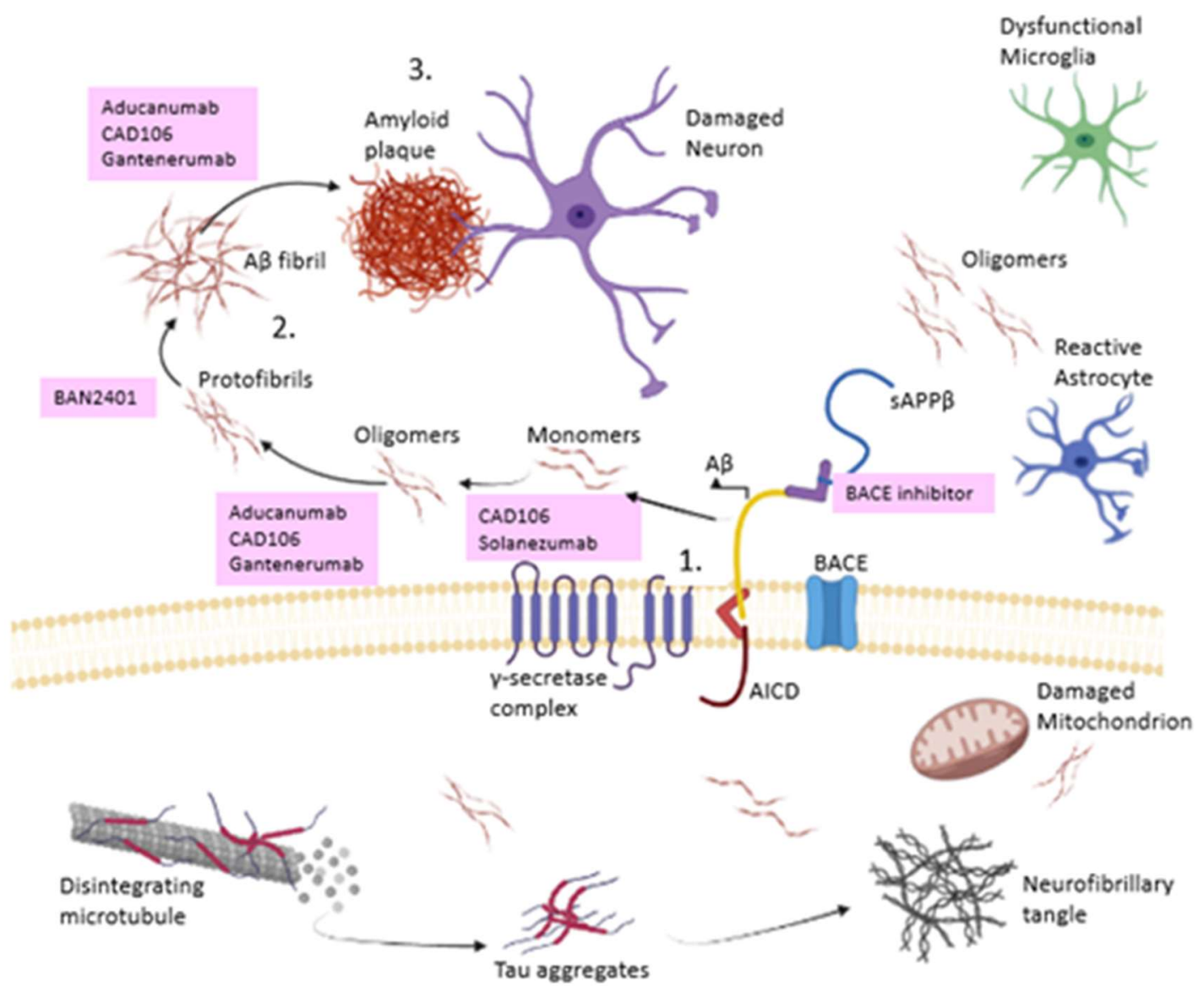

Figure 1 - The different $A \beta$ aggregated targets of the main anti-A $\beta$ drugs. Anti- $A \beta$ drugs (pink boxes) currently in phase III clinical trials for AD treatment. (1). A $\beta$ peptide formation from the cleavage of the APP with BACE1 and $\gamma$-secretase. (2). The $A \beta$ peptide self-associates into various aggregated forms; monomers, oligomers, protofibrils, and $A \beta$ fibrils. (3). These aggregative species further mature into amyloid plaques. Abbreviations: AICD: amyloid precursor protein intracellular domain; mAbs: monoclonal antibodies; sAPP $\beta$, soluble amyloid precursor protein- $\beta$. Figure created by the Author. 


\section{Crosstalk Between $A \beta$ and Tau}

The main function of tau proteins is to prevent microtubules from falling apart. Additional roles this microtubule-associated protein has include axonal extension, morphogenesis, and neuronal protein transport [37]. As illustrated above, once a microtubule is disintegrated, tau protein can aggregate from altered PTMs, such as acetylation or hyperphosphorylation, and form NFTs in the brains of individuals with $A D$ [3]. In addition to $A D$, other neurodegenerative diseases, such as frontotemporal dementia with Parkinsonism linked to chromosome 17 (FTDP-17), Down syndrome (DS), progressive supranuclear palsy (PSP), and Pick's disease (PiD), show hyperphosphorylated tau aggregation in the brain. Collectively these familial and sporadic neurodegenerative disorders are known as 'tauopathies' [38, 39]. Six different isoforms of human tau are expressed through the alternative splicing of exons 2, 3, and 10 in tau pre-mRNA [40]. In the normal adult brain, equal levels of 3R-tau and 4R-tau are expressed [41]. However, in several tauopathies, there is an altered ratio of $3 R / 4 R$ tau expressed through the disruption of tau exon 10 splicing [42-44]. In individuals with FTDP-17, intronic or silence mutations of the tau gene cause the altered ratios of 3R-4R-tau [42]. Tau exon 10 splicing disruption and an altered ratio of $3 R / 4 R$-tau is sufficient in inducing dementia and neurodegeneration [37]. Tau NFTs, along with insoluble $A \beta$ fibrils that form the amyloid plaque's core, are considered the main pathological hallmarks of $\mathrm{AD}[28]$.

There is compelling evidence that amyloid plaque deposits occur years, if not decades, before the formation of NFTs, brain atrophy, symptomatic changes, and spreading tau pathology [26, 45]. A particular prospective cohort study was conducted on patients with $\mathrm{MCl}$ and $\mathrm{AD}$, and it was observed that the deposition of $A \beta$ is prolonged and extended over two decades [45]. Hence, why the prediction of preclinical changes and $A D$ clinical phase onset are vital for facilitating the timing and design of effective therapeutic interventions. In accordance with the amyloid hypothesis, the hyperphosphorylation of tau is considered a downstream $A \beta$ deposition event. However, it is also possible that the pathways of $A \beta$ and tau act in parallel in causing $A D$ and enhancing their collective toxicity [2]. In addition, prevailing studies suggest that due to mutations in tau-coding genes, these NFTs can form independently of the toxic $A \beta$. The formation of the NFTs is thought to catalyse upstream $A \beta$ toxicity $[3,46]$, despite these tangles being associated more with memory loss, confusion, and neuron and synaptic decline $[3,47,48]$. Hence, either tau or $A \beta$ oligomers can function in damaging neuronal communication through synaptic damage. Therefore, synaptic loss prevention is a viable strategy to halt memory problems in $A D$ patients [3].

Interestingly, it has been indicated that tau hippocampal deposition in the absence of $A \beta$ may be inadequate in triggering the neurodegenerative process that leads to $A D$ [16]. However, findings from longitudinal studies with inherited or sporadic AD showed an increase in tau cerebrospinal fluid (CSF) biomarker levels during early AD stages, which declined after the manifestation of symptoms $[49,50]$. These findings are contradictory to the idea that rising levels of CSF tau in AD patients generally arise from dying neurons [16]. As a result, promising therapeutic approaches directed against tau aggregation must be pursued to prevent a therapeutic vacuum if present anti-A $\beta$ measures fail. Currently, antitau therapies are an active area of research, as targeting tau is considered more effective than the clearance of $A \beta$ upon the occurrence of clinical symptoms. 
Besides AD treatment, tau-targeting drugs are being examined in other tauopathies, including Pick's disease, FTDP-17, corticobasal degeneration (CBD), and PSP. Thus, treatments have wider applications [51]. Unfortunately, the majority of initial tau therapies based upon tau aggregation, kinase inhibition, or microtubule stabilization have been discontinued due to efficacy failures. However, current anti-tau therapies are immunotherapies and are providing promising results in preclinical studies [16, 51]. Due to the fact that tau and $A \beta$ aggregates have different temporal patterns of progression in the $A D$ brain, three different temporal $A D$ phases have been proposed; (1) Disruption of tau networks occurs in specific regions of the brain in clinically unaffected patients. (2) This tau disruption may trigger brain network changes that are associated with $A \beta$. (3) The deposition of $A \beta$ initiates the failure of the tau-associated network [16, 52].

\section{Treatment of AD}

As of June 2021 , only symptomatic therapies were available, and these are exclusively the AChE inhibitors and memantine as an $\mathrm{N}$ methyl-D-aspartate receptor antagonist. One AChE inhibitor, tacrine, is no longer available. However, three more: galantamine, rivastigmine, and donepezil, currently exist on the market [4]. In clinical trials, these symptomatic therapeutics showed improvements on the Mini-Mental State Examination (MMSE) and AD Assessment Scale-cognitive subscale (ADAS-cog), which are questionnaires and neuropsychological assessments used to specify cognitive impairments, respectively [53]. As a result of extensive progress in the understanding of $A D$ pathophysiology, large clinical developments, and huge expenditure on clinical trials, the first disease-modifying treatment for $A D$, aducanumab, achieved accelerated approval [5]. Prior to this, memantine, in 2003, was the last $A D$ drug to be approved. Suboptimal dosing, improper patient selection, inappropriate intervention times, and outcome measures are all proposed reasons for anti-A $\beta$ drug failures $[16,17]$.

Drugs that target $A \beta$ are one of the most studied areas in AD research. As seen in Table 1 , all the anti-A $\beta$ therapeutic strategies are targeted during the mild to moderate stages of $A D$. This excludes the terminated trials of Solanezumab and Verubecestat which recruited patients in the prodromal or $\mathrm{MCl}$ stage of $A D$. Generally, the strategies for anti$A \beta$ drug development fall under one of three main MOA. The three major MOAs employed in anti-amyloid disease-modifying treatments are (1) the reduction of $A \beta 42$ production through the use of $\mathrm{Y}$-secretase inhibitors, BACE1 inhibitors, and modulators of $\alpha$ secretase. (2) $A \beta$ plaque reduction with drugs that infer with metals or anti-A $\beta$ aggregation agents, and (3) $A \beta$ clearance promotion through passive or active immunotherapy. Passive $A \beta$ immunotherapy with mAbs is currently the most promising and active class [2]. In the past 20 years, most anti-A $\beta$ therapies were tested in LOAD forms of AD. However, some passive anti-A $\beta$ mAbs are being further reviewed in patients with EOAD, prodromal familial $A D$, and asymptomatic patients [16, 17]. 
Table 1 - Summary of the anti-amyloid $\beta$ therapeutic strategies in AD treatment.

* The status of these clinical trials is based upon that reported in ClinicalTrials.gov (https://clinicaltrials.gov).

Last accessed: 15th August 2021.

\begin{tabular}{|c|c|c|c|c|c|}
\hline $\begin{array}{l}\text { Drug (First } \\
\text { released) }\end{array}$ & $\begin{array}{c}\text { Mechanism of } \\
\text { Action }\end{array}$ & CT identifier & $\begin{array}{l}\text { Trial } \\
\text { Phase }\end{array}$ & Status & Ref(s) \\
\hline AN-1792 (2001) & Anti-A $\beta$ vaccine & NCT00021723 & II & Terminated & $\begin{array}{c}{[27,54,} \\
55]\end{array}$ \\
\hline $\begin{array}{l}\text { Tramiprosate/ } \\
\text { ALZ-801 (2007) }\end{array}$ & $\begin{array}{c}\text { A } \beta \text { aggregation } \\
\text { inhibitor (Small } \\
\text { molecule) }\end{array}$ & $\begin{array}{l}\text { NCT00314912, } \\
\text { NCT00088673, } \\
\text { NCT00217763 }\end{array}$ & III & $\begin{array}{l}\text { Active, not } \\
\text { recruiting }\end{array}$ & [55-57] \\
\hline $\begin{array}{l}\text { Bapineuzumab } \\
(2012)\end{array}$ & $\begin{array}{c}\text { Anti-A } \beta \\
\text { monoclonal } \\
\text { antibody }\end{array}$ & NCT00676143, etc & III & Terminated & {$[55,58]$} \\
\hline \multirow[t]{2}{*}{$\begin{array}{l}\text { Aducanumab } \\
\text { (2012) }\end{array}$} & \multirow[t]{2}{*}{$\begin{array}{c}\text { Anti-A } \beta \\
\text { monoclonal } \\
\text { antibody }\end{array}$} & $\begin{array}{l}\text { NCT01677572, } \\
\text { NCT02484547, } \\
\text { NCT02477800 }\end{array}$ & $\mathrm{I} / \mathrm{II} / \mathrm{II}$ & Terminated & \multirow[t]{2}{*}{$\begin{array}{c}{[55,57,} \\
59]\end{array}$} \\
\hline & & NCT04241068 & III & $\begin{array}{c}\text { Enrolling by } \\
\text { invitation }\end{array}$ & \\
\hline \multirow[t]{3}{*}{$\begin{array}{l}\text { Solanezumab } \\
\qquad(2013)\end{array}$} & \multirow[t]{3}{*}{$\begin{array}{c}\text { Anti-A } \beta \\
\text { monoclonal } \\
\text { antibody }\end{array}$} & $\begin{array}{l}\text { NCT01127633, } \\
\text { NCT01900665, } \\
\text { NCT02760602 }\end{array}$ & III & Terminated & \multirow[t]{3}{*}{$\begin{array}{c}{[55,58,} \\
60]\end{array}$} \\
\hline & & NCT02008357 & $\mathrm{II} / \mathrm{III}$ & $\begin{array}{l}\text { Active, not } \\
\text { recruiting }\end{array}$ & \\
\hline & & NCT01760005 & II/III & Recruiting & \\
\hline CAD106 (2014) & Anti-A $\beta$ vaccine & NCT02565511 & II & Terminated & $\begin{array}{c}{[55,61,} \\
62]\end{array}$ \\
\hline \multirow[t]{3}{*}{$\begin{array}{c}\text { Crenezumab } \\
(2014)\end{array}$} & \multirow{3}{*}{$\begin{array}{c}\text { Anti-A } \beta \\
\text { monoclonal } \\
\text { antibody }\end{array}$} & NCT01998841 & II/III & $\begin{array}{l}\text { Active, not } \\
\text { recruiting }\end{array}$ & \multirow[t]{3}{*}{$\begin{array}{c}{[16,55,} \\
63]\end{array}$} \\
\hline & & NCT02353598 & & Completed & \\
\hline & & $\begin{array}{l}\text { NCT02670083, } \\
\text { NCT03491150, } \\
\text { NCT03114657 }\end{array}$ & III & Terminated & \\
\hline \multirow[t]{3}{*}{$\begin{array}{c}\text { Gantenerumab } \\
(2014)\end{array}$} & \multirow{3}{*}{$\begin{array}{c}\text { Anti-A } \beta \\
\text { monoclonal } \\
\text { antibody }\end{array}$} & $\begin{array}{l}\text { NCT03444870, } \\
\text { NCT01760005 }\end{array}$ & II/III & Recruiting & \multirow[t]{3}{*}{$\begin{array}{l}{[16,55,} \\
64,65]\end{array}$} \\
\hline & & NCT03443973 & III & $\begin{array}{l}\text { Active, not } \\
\text { recruiting }\end{array}$ & \\
\hline & & $\begin{array}{l}\text { NCT01224106, } \\
\text { NCT02051608 }\end{array}$ & III & Completed & \\
\hline \multirow[t]{2}{*}{ CNP520 (2015) } & \multirow{2}{*}{$\begin{array}{l}\beta \text {-secretase } \\
\text { inhibitor }\end{array}$} & NCT02565511 & $\mathrm{II} / \mathrm{III}$ & Terminated & \multirow[t]{2}{*}{ [55] } \\
\hline & & NCT03131453 & III/III & Completed & \\
\hline $\begin{array}{c}\text { Lanabecestat } \\
\text { (2018) }\end{array}$ & $\begin{array}{c}\beta \text {-secretase } \\
\text { inhibitor }\end{array}$ & NCT02245737, etc & $\mathrm{II} / \mathrm{III}$ & Terminated & {$[16,55]$} \\
\hline $\begin{array}{c}\text { Verubecestat } \\
\text { (2018) }\end{array}$ & $\begin{array}{c}\beta \text {-secretase } \\
\text { inhibitor }\end{array}$ & $\begin{array}{l}\text { NCT01739348, } \\
\text { NCT01953601 }\end{array}$ & $\mathrm{II} / \mathrm{III}$ & Terminated & {$[16,55]$} \\
\hline $\begin{array}{c}\text { BAN2401/ } \\
\text { Lecanemab } \\
(2019)\end{array}$ & Anti- $A \beta \mathrm{mAb}$ & NCT03887455 & III & Recruiting & [55] \\
\hline
\end{tabular}




\section{Anti-Amyloid Disease-Modifying Treatments}

\section{The Reduction of $A \beta$ Production}

In accordance with the amyloid hypothesis, the sequential cleavage of the APP with $Y$ secretase and BACE1 gives rise to the amyloidogenic pathway. As a result, the inhibition of these secretases has been contemplated as a therapeutic approach against $A D$. However, $Y$-secretase also functions in cleaving different transmembrane proteins in addition to APP, for example, the Notch receptor 1 [2]. This receptor functions in controlling cell communication and differentiation and is partly responsible for recent clinical failures of $y$-secretase inhibitors namely, avagacestat, tarenflurbil, and semagacestat [60, 66, 67]. Safety concerns regarding the use of $\mathrm{y}$-secretase inhibitors limited their use for many years until this enzyme was capable of being therapeutically targeted safely [68]. There are currently no Ysecretase inhibitors in clinical trials [2]. However, in early 2021 Rynearson et al., presented promising results for a $y$-secretase modulator, namely compound 2 , that can safely and efficiently shift where the enzyme cuts the APP fragment at the C-terminal. This produces less toxic $A \beta 42$ [69]. BACE1 inhibition interferes with any $A \beta$ species or $A \beta$ aggregation upstream in the amyloid cascade [16]. The pharmacological inhibition of BACE1 is used as a therapeutic as the drugs reduce $A \beta$ levels in the AD brain [32]. Clinical trials with BACE inhibitors namely, verubecestat and lanabecestat have all recently been discontinued due to ineffectiveness, safety reasons, and lack of efficacy, respectively [2, 70, 71]. A dose-dependent and significant reduction of CSF $A \beta 42$ was observed in all agents. However, these results indicated no functional or cognitive benefit and show how
BACE1 inhibitors may be incapable of halting the progression of $A D$ [72].

\section{The Reduction of $A \beta$ Plaque Burden}

Aggregation inhibitors prevent the formation of $A \beta 42$ fibres by directly interacting with the $A \beta$ peptide. These inhibitors are considered to be a potential $A D$ therapeutic. However, the oral drug scyllo-inositol (ELND005) was the last A 342 inhibitor to be tested in humans over ten years ago. Phase II clinical trials with $A D$ patients provided no evidence of clinical improvements with ELND005 and serve toxic infections associated with this oral agent led to the forced cessation of trials [73]. Currently, the use of peptidomimetics that mimic specific peptides is in development, such as the $\mathrm{Y}$ AApeptides as they partially reverse and inhibit the aggregation of $A \beta 42$. Drugs that interfere with metals are capable of $A \beta$ plaque reduction. This is because $A D$ pathophysiology has strong links with dyshomeostasis and the abnormal accumulation of certain metal ions, for example, zinc, iron, and copper [2]. PBT2 is a metal protein-attenuating drug that has shown promising preclinical data during a three-month phase II AD treatment trial. PBT2 treatment reduced CSF $A \beta$ by $13 \%$ and a dose-related improvement in cognitive function was observed in early AD patients [74].

\section{The Promotion of A $\beta$ Clearance}

Active and passive immunization are the main immunotherapeutic approaches in $A D$ treatment that are involved in promoting $A \beta$ clearance [2]. During the process of active immunization, phosphorylated tau (ptau) peptides, $A \beta$ peptides, or polymerized British artificial amyloidosis (ABri)- related peptides (pBri) are utilised as immunogens. These immunogens are presented to B cells through the action of antigen-presenting cells. Using ptau and $A \beta$ peptides will produce antibodies 
to their respective epitopes. However, both ptau and $A \beta$ epitopes are produced from the use of pBri peptides [75]. In passive immunization, the mAbs to ptau and $A \beta$ epitopes are systemically infused for the penetration of the blood-brain barrier (BBB). As these mAbs cross this BBB, they degrade, clear, or neutralise or disaggregate their specific targets [2]. Once the innate immune system is stimulated by either active or passive immunization, the amelioration of $A D$ pathology is promoted through the function of macrophage [75]. Overall, the promotion of $A \beta$ clearance seems a promising avenue if utilized very early in the progression of $A D$, prior to any disease symptoms. As a result, these $A \beta$ targeting strategies are currently in development in preclinical $A D$ trials.

\section{Active Anti-A $\beta$ Immunotherapy}

Active immunotherapy offers the long-term production of antibodies from only a short-term administration of drugs. Conversely, the first candidate of active anti- $A \beta$ vaccines for $A D$ patients was marred by an ill-fated clinical trial of $\mathrm{AN}-1792$ in 2002 [27, 29]. This vaccine contained pre-aggregated $A \beta 42$ with the immunological adjuvant QS21 [29]. Initially, in phase I clinical trials with AN-1792, it elicited a promising immunological response. However, one patient became severely unstable and passed away from a pulmonary embolism one year after her last AN-1792 vaccine. Postmortem analysis indicated the patient developed $T$ cell-mediated meningoencephalitis, an inflammation of the brain's protective membranes [76]. The exact cause of meningoencephalitis remained unclear [27]. Although, it had been suggested that an excessive Th1 response was likely the cause based on evidence from cytotoxic $T$ cells which surrounded the cerebral vessels [27]. This phase I study showed the vaccine cleared most $A \beta$ deposits in the brain but produced no clinical or cognitive benefits due to its small case numbers [54]. Subsequently, an additional phase II active immunization study began. However, around $6 \%$ of $\mathrm{AN}-1792$ treated patients developed a similar type of $\mathrm{T}$ cell-mediated meningoencephalitis [27]. More recent $\mathrm{AN}-1792$ immunization trials have confirmed a reduction in the $A \beta$ plaque burden from active immunization with fibrillar $A \beta$ proteins [77, 78]. In order to avoid the $T$ cell epitopes located at the C-terminus, secondgeneration vaccines, such as the $A \beta$ vaccine, ACC-001, and the immunotherapeutic agent, CAD106, have sought to only create anti-A $\beta$ antibodies at the $\mathrm{N}$-terminus [16, 29, 79-81].

Until early 2021, CAD106 is the only active anti-A $\beta$ vaccine in phase III trials $[17,29,62]$. Antibodies elicited from CAD106 react with $A \beta$ monomers and oligomers. Combination trials with CAD106 and a small molecule inhibitor of BACE1, called CNP520 were developed to remove amyloid plaques and reduce $A \beta$ generation, respectively [3]. As of late 2019, CNP520 was discontinued as it was linked to a worsening cognitive score on the Repeatable Battery for the Assessment of Neuropsychological Status (RBANS) which measures the five cognitive domains of memory, attention, language, executive functions, and spatial. Also, individuals in these trials had an increase in brain atrophy [82]. Other combination trials are hoped to be beneficial in late-stage AD patients as BACE1 inhibition may be insufficient and too late for elderly AD patients [3].

\section{Passive Anti-A $\beta$ Immunotherapy}

Early $A D$ intervention is being attempted through secondary prevention trials with mAbs. Secondary prevention trials only recruit preclinical or asymptomatic individuals who have positive $A D$ biomarkers and not just a random selection of asymptomatic individuals 
from the general public, as seen in primary prevention trials [83]. Passive immunization with anti-A $\beta$ mAbs may potentially be involved in a preventative way of modifying the course of $A D$ before clinical symptoms and widespread brain damage occurs [32]. Valuable lessons have been gained from previous failed phase III clinical trials with the mAbs solanezumab and bapineuzumab [54, 58]. Nowadays there are strict criteria for inclusion, such as amyloid positivity on biomarkers as part of secondary prevention trials. Furthermore, study designs became more accurate for specific targets, such as $A \beta$ plaque reduction on amyloid $\mathrm{PET}$, and higher dosing was made a requirement to avoid ARIA and $\mathrm{APO} \& 4$ genotyping [2].

In 1999, Schenk and his colleagues first demonstrated how immunization with the $A \beta$ peptide reduced plaque deposits in mice brains. These mice were genetically modified to experience AD symptoms similar to humans [84]. Three different hypotheses were later developed on the basis that $A \beta$-specific antibodies reduce AD symptoms (Fig. 2) [17]. It is vital to understand the three MOAs used in anti-amyloid disease-modifying treatments in order to develop more effective and safer immunotherapeutics. The hypotheses that have arisen are dependent on the efficiency of the antibody to enter the central nervous system (CNS) and take effect there or whether the antibody is located in the periphery, which is sufficient enough to give beneficial results [27]. The first hypothesis (1) involves the direct action of anti-A $\beta$ antibodies against $A \beta$ oligomers, protofibrils, fibrils, or $A \beta$ plaques, where the binding destabilised these aggregate species [17]. Secondly, (2) the involvement of microglia-mediated by fragment crystallizable $(F c)$ receptors which initiates phagocytosis of $A \beta$ and complement activation [85]. Lastly, (3) the 'peripheral sink' hypothesis suggests that amyloid equilibrium through the BBB is changed following free concentrations of $A \beta$ in the blood. The antibodies do not cross the $B B B$ but bind to $A \beta$ circulating in the plasma, thus creating a concentration gradient and net efflux of $A \beta$ from the brain to the blood and plasma [31]. It is still unclear whether the entry of anti-A $\beta$ mAbs through the brain is required.

It has been proposed that past clinical failures with mAbs can be attributed to their poor CNS penetration, as only $0.1 \%$ were capable of crossing the BBB [86]. Attempts to improve mAbs penetration into the brain have focused on gene encoding antibody delivery, expression induction, and receptor targeting in the BBB to allow for the induction of active transport of the mAbs into the CNS [29]. The mechanism of action of mAbs is to initially capture the target where the secondary effector function is linked at the $\mathrm{Fc}$ domain of the mAbs. A differentiating point in the mAbs is their Fc region, which is invariable. Its interaction with microglial immune cells mediates phagocytosis and degrades the antigen-antibody complex [31]. 


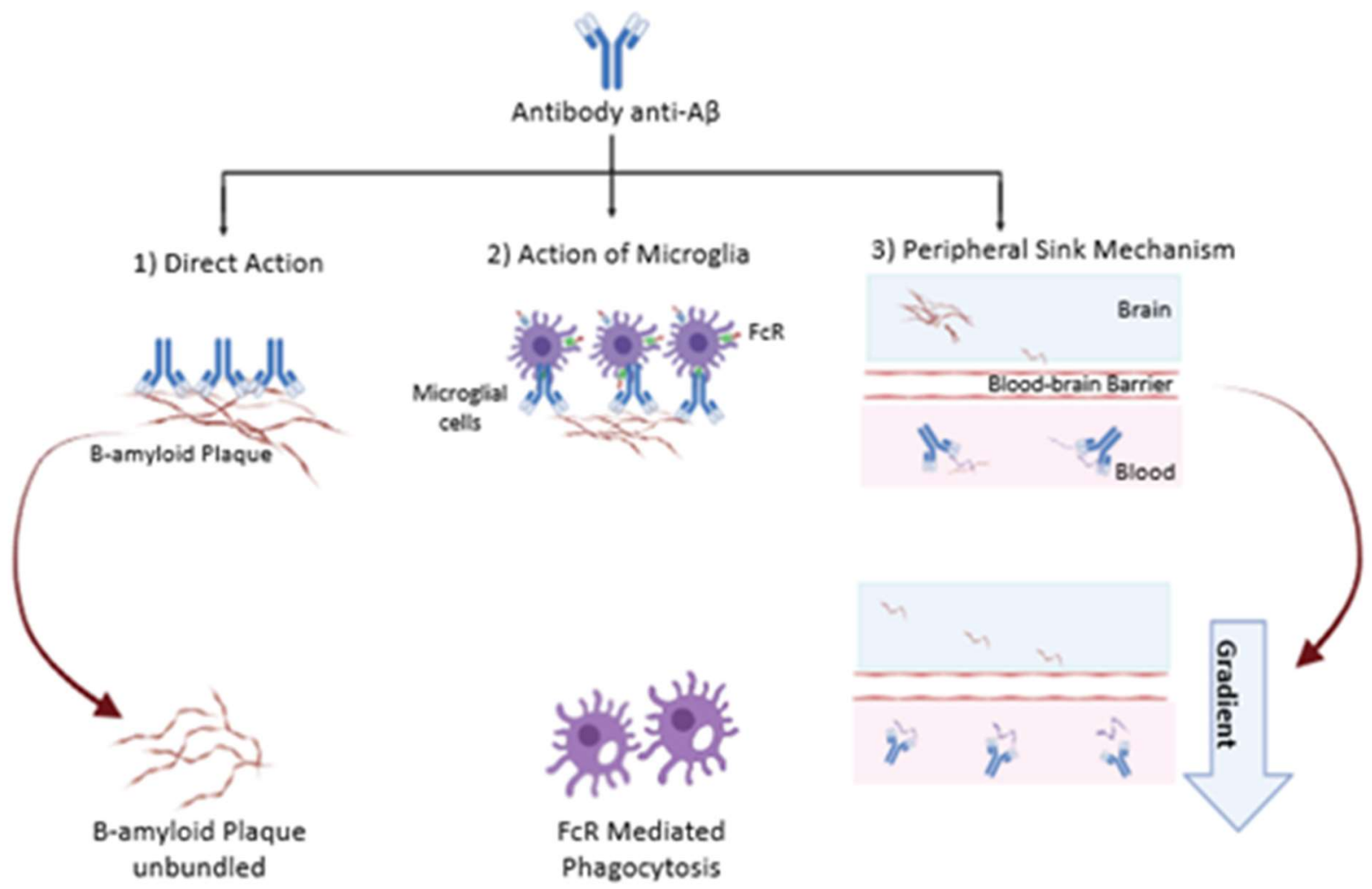

Figure 2 - The three main mechanisms of $A \beta$ removal via specific antibodies. (1) Anti- $A \beta$ antibodies in direct action against the aggregated forms of $A \beta$. (2) Microglia activation initiates the phagocytosis of $A \beta$. (3) $A \beta$ is removed via antibody binding and the generation of a net efflux from the brain to the plasma. Abbreviations: FcR: Fc receptors. The different $A \beta$ aggregated targets of the main anti-A $\beta$ drugs. Figure created by the Author.

\section{Differential Selectivity in $A \beta$ Oligomers}

The severity of $A D$ correlates strongly to the level of non-fibrillar, soluble $A \beta$ oligomers. This suggests these soluble $A \beta$ species, rather than the fibrils in amyloid plaques, likely play a vital role in $A D$ pathology. $A \beta 42$ has the strongest intrinsic tendency to self-aggregate compared to the other oligomeric species, even $A \beta 40$, which is produced in a higher abundance [87]. Conversely, $A \beta 40$ has been reported to be unaltered in $A D$. However, its concentration ratio with $A \beta 42(A \beta 42 / 40)$ is suggested to be more efficient than the concentration of $A \beta 42$ alone in diagnosing individuals with $A D$ [88]. To date, there is a lack of comprehensive reviews on the use of the $A \beta 42 / 40$ ratio for $A D$ diagnosis [89]. Currently, mAbs in clinical trials are focused on addressing both $A \beta 42$ and $A \beta 40$ isoforms. Various soluble oligomers aggregate during the formation of amyloid, all with different structures, shapes, sizes, and hydrophobicity content [35]. As these variations occur, characterization between different soluble oligomeric aggregates is essential in determining how specific function relates to disease progression. On this basis, recent advances have been made on generating various mAbs capable of recognising the specific epitopes of $A \beta$ in order to hinder its aggregation [35]. These mAbs can 
be administered in an injection or infusion [31]. The majority of mAbs in development are human immunoglobulin $\mathrm{G}$ (IgG1) derivatives. IgG1s are the same subtype of antibody capable of inducing pro-inflammatory cytokine release including IL-1 $\beta$, TNF-, and IL-6, hence why specific side effects can occur [26].

Aducanumab, gantenerumab, and BAN2401 are all human or humanized mAbs capable of binding to aggregated forms of $A \beta$ with high affinity. This binding promotes $A \beta$ removal by Fc receptor-mediated phagocytosis. Each of these antibodies shows different selectivity to $A \beta$ soluble oligomers when compared to the insoluble amyloid plaques and fibrils [57].

Aducanumab, gantenerumab, and BAN2401 all bind primarily to insoluble and soluble aggregates [28]. A major drawback in the current clinical trials of passive immunotherapy is the lack of specific targeting in most toxic $A \beta$ oligomers, for example, aducanumab and gantenerumab bind to $A \beta$ fibrillation or aggregates, while crenezumab can recognise different $A \beta$ forms [90-93]. Through the 'peripheral sink' hypothesis, the antibody that targets soluble $A \beta$ may play a role in the preclinical stages of AD. The mAbs should be treated in EOAD in order for their therapeutic effect to be enhanced prior to cognitive or synaptic impairment. Patients who are already experiencing $A D$ symptoms will likely show no significant effect from using these anti-A $\beta$ drug treatments [94].

\section{Current mAbs in Clinical Trials}

There are many mAbs trials currently underway in mild and prodromal $A D$ cases, including aducanumab, gantenerumab, and BAN2401 (Table 1). Also, gantenerumab is in studies for at-risk and preclinical individuals [2]. The initial results from the aducanumab and BAN2401 trials suggest that there is a reduction in the cerebral amyloid burden and a declaration of cognitive decline identified based on these treatments in individuals with very mild and prodromal $\operatorname{AD}[65,95]$. Contrary to this, the initial preliminary clinical trial results of gantenerumab in prodromal $A D$ patients were stopped prematurely due to lack of efficacy [96]. Further analysis was completed and higher gantenerumab doses were suggested for efficacy, and as a result, an extension with more mild $A D$ participants was continued alongside a placebo-controlled double-blind study with individuals with mild $A D$ [97]. The lack of efficiency so far with anti$A \beta$ mAbs may reinforce the case against the amyloid hypothesis. However, encouraging results with some mAbs equally make completely dismissing this hypothesis difficult [29].

Converging evidence over the last two decades has suggested that the soluble oligomers are the most neurotoxic species of $A \beta$ and are the target of most mAbs [1]. Montoliu-Gaya and Villegas reviewed that targeting the $N$-terminus region of the $A \beta$ peptide is the most effective method for the mAbs in clearing the neurotoxic aggregated species [98]. The success of $\mathrm{N}$-terminal targeting mAbs is attributed to phagocytosis and microglial activation, which are hypothesised to be the main features of aducanumab, gantenerumab, and BAN2401. Transgenic mouse models demonstrated that the mAbs cross the BBB to bind specifically to $A \beta$ in amyloid plaques [29]. Once mAbs cross the BBB, they can achieve sustained brain concentrations at levels that are efficient in removing or inhibiting $A \beta$ oligomers [57]. However, a major concern with current mAbs is the limitations that exist in using transgenic mouse models. The mice are modified to match the physiological and genetic states in humans. However, differences do exist, thus limiting the translatability of preclinical findings in mice to actual trials in humans with sporadic 
$A D$. Furthermore, in mice that overexpressed $A P P$, anti-A $\beta$ mAbs worsened their neuronal dysfunction [8].

In clinical trials, aducanumab and gantenerumab required around five months of a titration regimen in dosing for peak brain levels to reach a steady state [57]. The administration of the highest intravenous dose of aducanumab (10 mg/kg) monthly was needed to achieve clinical efficacy [2]. In contrast, BAN2401 is expected to achieve constant peak brain levels in approximately two and a half months, based on $10 \mathrm{mg} / \mathrm{kg}$ dosing twice monthly. Considering that no titration period is required, BAN2401 may have an earlier onset of clinical efficiency than aducanumab [57]. The clinical efficacy of some monoclonal anti-A $\beta$ mAbs, specifically gantenerumab, solanezumab, and crenezumab, are being evaluated under two preventative studies, Alzheimer's Prevention Initiative (API) and Dominantly Inherited Alzheimer Network (DIAN-TU) in asymptomatic subjects. Both API and DIAN are very sensitive composite scales to cognitive decline. Much higher doses of the mAbs are being used than in previous trials in patients with sporadic AD [32]. If the studies from API and DIAN reject the hypothesis, it should be concluded that the amyloid hypothesis is invalid in sporadic and genetic forms. If the hypothesis is supported, it may be concluded that the two forms have critically different mechanisms [17]. These two trials have the potential to indirectly influence the clinical results of other mAbs currently in clinical trials, such as aducanumab and BAN2401, in individuals with sporadic AD [32].

\section{Aducanumab - Recent Approval}

Aducanumab was co-developed by Biogen and Eisai under a licence from the biopharmaceutical company Neurimmune for
AD treatment [99]. On June 7th 2021, the USA FDA conditionally approved the EMBARK (NCT04241068) trial of aducanumab [5]. Currently, Aducanumab is under regulatory review in Europe and Japan, and multinational phase $3 \mathrm{~b}$ clinical studies are ongoing to test its long-term safety and tolerability [59, 100]. ENGAGE (NCT02484547) and EMERGE (NCT02477800) identical phase III clinical trials began simultaneously in autumn 2015 to provide evidence of Aducanumab's efficacy and safety. Individuals included in these trials had mild $A D$ or $\mathrm{MCl}$, a Clinical Dementia Rating-Sum of Boxes (CDR-SB) score of 0.5, MMSE score of $\geq 24$, and positive amyloid PET scans. However, the development of aducanumab was discontinued in March 2019 as Biogen revealed that this $\mathrm{mAb}$ had failed its futility analysis in both the ENGAGE and EMERGE trials [101, 102]. This failure was added to the list of pre-existing failures in therapeutics aimed at alerting cognitive decline and removing $A \beta$ plaques [103]. These failures include the humanised $m A b$, solanezumab, which failed to affect cognitive decline, and the BACE-1 inhibitor, verubecestat, which did reduce $A \beta$ brain levels by $90 \%$, but failed to change AD trajectory $[104,105]$.

It came as a shock to the AD community when, in October 2019, Biogen filed a Biologics License Application (BLA) request to the US FDA for the approval of aducanumab following a post futility analysis of the EMERGE, as results were 'trending positive' [106]. Some researchers in the area of $A D$ criticise this statement, as this effect could have been as a result of a $6 \%$ worsening in placebo groups, not the higher dose exposure as claimed by Biogen [101]. Biogen's comparison between EMERGE and ENGAGE was done in a way to be supportive of EMERGE as the positive trial, in order to show the effectiveness of aducanumab so it would be accepted by the FDA [8]. This sparked controversy in the 
resurrection of aducanumab. Upon MMSE and CDR-SB exams, individuals taking aducanumab did show signs of slowing $A D$ progression. Although this data remains controversial as the absolute difference determined by CDR-SB between the experimental and placebo groups was $0.4 / 18$, whereas the relative difference was $23 \%$ [28, 101]. Additionally, the outcome of this trial may have been skewed through the potential contribution of APOE $\varepsilon 4$ subjects in the treatment and control cohorts [103].

\section{Evaluation Measures}

Determining $A D$ biomarkers has been of major focus in $A D$ diagnosis given the significance of the amyloid hypothesis, being on reliably measuring $A \beta$, and to a lesser extent, tau levels in the brain [8]. Evaluation measures of $A D$ are primarily classified into either fluid or imaging biomarkers [107]. CSF is used indirectly as a diagnostic tool in measuring potential biomarkers of $A D$, which include phosphorylated tau ( $p$-tau), total tau (t-tau), and $A \beta$ levels [3]. Measuring $A \beta$ levels from CSF samples is invasive. However, these findings indicated that reduced $A \beta 42 \mathrm{CSF}$ concentrations in $A D$ patients correlated with the aggregation of $A \beta$ deposits [8]. Therefore, upon the revision of the 2018 National Institute on Aging and Alzheimer's Association (NIAAA) diagnostic guidelines, $A \beta 42$ and other amyloidogenic peptides were accepted as candidate AD biomarkers [108]. However, contradictory theories and results exist regarding what concentrations of $A \beta$ and tau are necessary for $A D$ diagnosis in the prodromal stages. For example, the concentrations of CSF A 342 have decreased, increased, or have shown no real change as the cognitive functions of $A D$ individuals continue to deteriorate [109-113].
Preventative therapeutic methods can be developed from screening for $A D$ in its early stages. PET and MRI are types of neuroimaging techniques used to show a gradual and progressive cognitive decline in $A D$. Amyloid-PET is the most reliable imaging diagnostic tool as it distinguishes aggregated $A \beta$ in the brains of $A D$ patients [107]. Florebetapir is a ligand used in amyloid-PET imaging that is efficient in detecting the deposition of amyloid. Once this ligand is absorbed through the BBB, it washes out the grey matter brain tissues that lack amyloid [57]. Only patients showing a clear $A D$ signature from biomarkers or imaging are recruited in $A D$ trials, and treatment is started in patients with early and prodromal AD [114].

Florebetapir PET imaging showed that aducanumab treatment led to the reduction of $A \beta$ plaques in the brain when completed in a time and dose-dependent manner [23]. On this basis, positive biomarker effects on amyloidPET resulted in aducanumab's reanalysis in October 2019, following its failed futility analysis in March of that year [57]. Nonetheless, previous failures in anti-A $\beta$ therapeutics can partly be attributed to patients who enrolled in $A D$ trials that lacked significant evidence of $A \beta$ brain deposition from biomarkers. Up to $25 \%$ of patients with mild $A D$ enrolled in these past trials and they did not have any evidence of $A \beta$ deposition [32]. The new NIA-AA diagnostic criteria defined what the preclinical stages of $A D$ are in order for early pharmacological intervention to take place during secondary prevention trials [2, 32].

\section{Clinical Efficacy of Anti-A $\beta$ Therapeutics}

The mAbs that primarily target $A \beta$ aggregates all have potential for clinical efficacy [94]. Currently, the EMBARK study enrols around 
2400 patients that previously participated in aducanumab clinical trials, including the PRIME (NCT01677572), ENGAGE, and EMERGE studies. The main objective of this trial is to evaluate the tolerability and safety of monthly $10 \mathrm{mg} / \mathrm{kg}$ aducanumab doses after feeder studies are discontinued [59]. However, recurrent failures in clinical trials with $m A b s$ and other anti-A $\beta$ therapeutics have casted doubts about the efficacy and effectiveness of these treatments (Table 1). Aducanumab and BAN4201 showed a slowdown in cognitive decline through positive biomarker effects in reducing cerebral amyloid in patients experiencing mild and prodromal $A D$ [2]. In contrast, gantenerumab lacked clinical efficacy, despite showing significant biomarker effects from reductions in both CSF tau parameters (t-tau and p-tau) and amyloid [57]. Therefore, higher dosing of gantenerumab was suggested, and currently, a placebo-controlled, double-blind trial in mild $A D$ patients is underway [29].

The majority of mAbs in development are $\lg G$ derivatives and, as mentioned previously, this contributes to the observed side effects like ARIA [26]. It was in anti-amyloid antibody therapeutics, where safety issues, such as amyloid-related imaging abnormalities with edema (ARIA-E) or with microhaemorrhages (ARIA-H), were first reported [115]. The amyloid burden in the vasculature of patients seems to correlate with the occurrence of these side effects [115]. mAbs are capable of binding to the vascular deposits and recruiting lymphocytes and monocytes to facilitate amyloid clearance. As a result, brain vessel wall function is weakened, causing interstitial fluid to enter brain tissues, as in the case with ARIA-E. The strongly stimulating phagocytosing IgG subtypes are more prone to ARIA-E [26]. ARIA risk increases with the dose of mAbs, suggesting a correlation between imaging abnormality and how effective the amyloid clearance is [94]. Also, previous studies have indicated a close correlation with safety issues to cerebral amyloid clearance on PET imaging. BAN2401 showed the lowest rate of ARIA-E at $10 \%$, consistent with its lower affinity for amyloid plaques than aducanumab and gantenerumab [57]. At each dose of aducanumab and gantenerumab across all genotypes, the rate of ARIA-E was $30 \%$ or higher in their respected phase III clinical trials $[116,117]$.

APOE $\varepsilon 4$ carriers have a higher risk of developing $A D$ and represent over $65 \%$ of $A D$ sufferers [118]. When treated with mAbs, these individuals have an increased risk of ARIA-E or ARIA-H due to the rapid removal of amyloid plaques from the brain vessels [115]. As carriers have a higher burden of neurotoxic $A \beta$, they are the optimal group for initial approval of anti-A $\beta$ drugs and efficacy studies. More $A \beta$ oligomers are targeted at higher doses, which supports its efficacy. However, amyloid plaques are also bound, and this off-target effect triggers the significant dose-limiting ARIA-E side effect [118]. Despite the efficacy of aducanumab in APOE $\varepsilon 4$ carriers currently being unknown, the rate of ARIA-E was $\sim 42 \%$, compared to $\sim 35 \%$ in the overall study population [116]. A higher clinical efficacy with APOE $\varepsilon 4$ carriers was seen in trials with BAN2401. However, ARIA-E incidence was increased from $\sim 10 \%$ in the overall study population to $\sim 15 \%$ in carriers [119]. AmyloidPET imaging of aducanumab and BAN2401 showed very high efficacy in plaque clearing. However, there is consistent evidence across studies, suggesting that prolonged engagement of the soluble $A \beta$ oligomers at high doses is needed for clinical benefit. Clinical efficiency is not explained by the clearance of plaques alone, and plaque formation may just be a protective mechanism for the $A \beta$ oligomers in limiting their neurotoxicity [120]. 


\section{Preventing AD}

There is currently no cure to halt $A D$ progression. Disease modification represents around $75 \%$ of all the current therapeutic approaches in the $A D$ pipeline, including the recently approved $\mathrm{mAb}$ aducanumab [5, 32]. Nonpharmacological treatments include lifestyle interventions, such as a healthy diet, mental challenges, exercise, and socialization. For example, taking antioxidants has proven to compensate for the age-related downregulation of $\alpha$-secretase, which is needed in preventing the formation of $A \beta$ peptide [25]. There is a substantial body of evidence supporting the use of BACE1 inhibitors in $A D$ prevention as it turns off toxic $A \beta$ production [3]. Firstly, BACE1 inhibition had a direct effect in studies with transgenic mice overexpressing human APP in individuals with familial AD mutations [121-123]. Secondly, there was a $40 \%$ decrease in the production of $A \beta$ in vitro due to rare human mutation at the cleavage site of BACE1, suggesting BACE1 cleavage alone may be beneficial [124, 125]. However, inefficiencies in BBB penetration were noted with the BACE1 inhibitors [26]. Therefore, few BACE1 inhibitors are currently in development due to increases in toxicity in humans [16]. It is hoped that BACE1 inhibition will be more effective in combination with immunotherapy [3]. The secondary mAbs aducanumab, gantenerumab, and BAN2401prevention trials are currently being tested in patients experiencing the preclinical stages of familial $A D$, early $A D$, and high-risk asymptomatic patients. Preliminary results from these trials support the amyloid hypothesis as the elevation of $A \beta$ levels is represented in the early stages of $A D$, demonstrating the feasibility of secondary prevention trials during the preclinical stages of $\mathrm{AD}[32]$.

\section{Future Perspectives}

The ultimate proof for the amyloid hypothesis would be that intervention in the amyloid cascade would prevent cognitive deterioration and neuronal loss [31]. A single-targeted approach to $A D$ treatment has not produced any effective therapies yet, so future treatments are focusing on combination therapies to try and target the multiple mechanisms of $A D$, from its molecular biology to its various cellular pathways [36]. Combination therapies are thought to be the future of $A D$ prevention and treatment [3]. The inhibition of BACE1 and $\gamma$-secretase to reduce $A \beta$ production and the use of active and passive immunotherapy to enhance $A \beta$ clearance have both failed to demonstrate therapeutic effects in patients with moderatemild $A D$ [16]. The $A D$ scientific community suggested that this moderate-mild AD stage is too late for the anti-A $\beta$ drugs to work in reversing or halting $A D$ progression. Therefore, current $A \beta$-directed pharmacological interventions focus on patients in the preclinical stage or are asymptomatic [32].

Approaches that target more than one cellular system in $A D$ are being developed using small molecule drugs as combination therapies that target the vast amyloid cascade. ALZT-OP1 is a combination therapy consisting of cromolyn sodium and ibuprofen. Ibuprofen is a nonsteroidal anti-inflammatory (NSAID) drug that has been proven to reduce $A \beta 42$ levels by modulating the activity of the $\gamma$-secretase complex. Cromolyn sodium induces microglia transition to a pro-phagocytic state from a proinflammatory, inhibiting $A \beta$ accumulation [32]. In combination, this therapy promisingly appears more effective, less costly, and safer than other anti-A $\beta$ therapeutics [26]. ALZ-801 is another small-molecule drug that avoids the limitations experienced with the higher-dosing mAbs [57]. ALZ-801 is a tramiprosate prodrug 
capable of regulating the conformational flexibility of the $A \beta 42$ isoform, therefore inhibiting oligomer formation [36]. Tramiprosate showed a dose-dependent decrease in the assessment of hippocampal atrophy by MRI, making it the only drug to date to show a positive result in brain atrophy prevention [126]. The use of ALZ-801 is the next generation in selective anti-A $\beta$ therapeutics as it has an improved product profile and selectivity to oligomers compared to the mAbs. ALZ-801 provides a probable preventative treatment in presymptomatic patients [57].

\section{CONCLUSION}

The amyloid hypothesis has been debated for years, despite being supported by amyloid imaging techniques [26]. Initially, it was proposed that insoluble aggregates of $A \beta$ fibrils were the core hallmark of AD. However, the updated hypothesis suggests that soluble oligomers play a more significant role in neurotoxicity [16]. Despite the strong body of evidence that confirms the toxic nature of amyloid, very few anti-amyloid agents have been shown to have cognitive benefits whilst fulfilling the specific criteria for selection [57]. In the past, drugs primarily focused on targeting $A \beta$ accumulation rather than the removal of $A \beta$ via anti-A $\beta$ agents, so ongoing failures may be attributed to selecting the wrong biological target [17]. However, drugs against $A \beta$ have failed in both the advanced and early stages of the disease, casting doubt on the amyloid hypothesis [32].

The inclusion of non-AD patients in previous trials is the reason current trials only recruit patients with positive $A D$ biomarker signatures [26]. Plasma tau is a non-invasive biomarker compared to measuring CSF levels. Nonetheless, it is limited from a substantial overlap in normal aging and $A D$, so its use as a stand-alone biomarker is not supported [8]. The source of neurodegeneration is thought to be from $A \beta$ pathology acting through tau. However, even in young individuals, tau pathology is observed in autopsy studies before the marked deposition of $A \beta$ [16]. Furthermore, brain imaging of individuals with preclinical $A D$ suggests that the initial emergence of neurodegeneration biomarkers, such as reduced glucose metabolism and hippocampal volume, aren't dependent on $A \beta$ amyloidosis [17].

In light of the promising late-stage trials with gantenerumab, BAN2401, and aducanumab advanced approval, a major challenge in their future development is devising a preventative way to avoid ARIA [5, 26]. Progressive, slow dosing of mAbs is a preservation method against forming the initial vascular burden [26]. Targeting specific epitopes that are absent in the vascular amyloid, such as $A \beta 42$, might reduce the binding of antibodies to the vessels [35]. Finally, improvements of antibody passage through the BBB from modifying targeting Fc receptors can reduce dosage, thereby reducing side effects. This strategy can increase the brain penetrance of mAbs [127]. However, the loss of antibody affinity is experienced. Future research should explore how other mAbs could be made safer to avoid their apparent tendency to deteriorate cognitive function compared to placebo groups [17]. Shortcomings in treatments have led to other techniques, such as focused ultrasound (FUS), which have been indicated to increase drug penetration through the BBB and increase the overall efficacy of mAbs [26].

Despite $A D$ being the most prominent neurodegenerative disease globally, pharmacologic treatments have been extremely limited, with a few approved drugs providing only symptomatic treatments [4]. By managing $A D$ symptoms, patients can be 
provided with independence, dignity, and comfort for longer. The AChE inhibitors galantamine and donepezil show the highest efficacy levels for cognition in patients with mild to moderate $A D$. Whilst the best profile for acceptability is seen with the N-methyl-Daspartate receptor antagonist memantine [128]. These drugs control or reduce the behavioural and cognitive symptoms associated with the disease [4]. However, these symptomatic treatments are not a cure.

Aducanumab's recent accelerated approval in June 2021 marks a promising chapter for anti$A \beta$ therapeutics, as it represents the first disease-modifying drug conditionally approved to treat early AD [99]. Biogen's surprise reversal puts hope on the horizon for additional $A D$ therapeutics [5]. Although this $m A b$ is currently only available in the US, its approved status depends on its long-term tolerability and safety results in ongoing clinical trials [30]. As over $35 \%$ of patients experienced ARIA-E with aducanumab treatment, there is a need to improve A $\beta$-targeting precision [116]. Therefore, careful evaluation of the safety and efficacy of anti-amyloid therapeutics is vital, especially for APOE $\varepsilon 4$ carriers, in determining the benefit-risk profile [57].

In the face of the repeated failures of anti-A $\beta$ therapeutics, the anti-A $\beta$ mAbs remain the most advanced drugs in development for $A D$ treatment. The plethora of $\mathrm{mAb}$ clinical trials has helped develop an understanding of the mechanism of disease, while supporting the amyloid hypothesis. Overall, the tolerability and safety profile of these mAbs has been acceptable, along with promising biomarkers and clinical effects [32]. Serious complications are rare and must always be compared against the alternative consequences of untreated $A D$ [29]. Should confirmation of aducanumab's efficacy prevail, its researchers should be met with a great debt of gratitude from the $A D$ community, not only for producing the first disease-modifying treatment, but also for opening the door to promising anti-A $\beta$ therapeutic advances.

\section{ACKNOWLEDGEMENTS}

I would like to thank my supervisor, Dr. Stephen Rea, for all his guidance and helpful discussions throughout the preparation of this review.

\section{AUTHOR'S NOTE}

All figures, or tables, were created by the Author, unless otherwise mentioned in the description provided of said figure.

\section{REFERENCES}

[1] D. J. Selkoe and J. Hardy, "The amyloid hypothesis of Alzheimer's disease at 25 years," EMBO Mol Med, vol. 8, no. 6, pp. 595-608, Jun 2016. Available: https://doi.org/10.15252/emmm.201606210.

[2] K. G. Yiannopoulou and S. G. Papageorgiou, "Current and Future Treatments in Alzheimer Disease: An Update," Journal of Central Nervous System Disease, vol. 12, p. 1179573520907397, 2020. Available: https://doi.org/10.1177/1179573520907397.

[3] B. Das and R. Yan, "A close look at BACE1 inhibitors for Alzheimer's disease treatment," CNS drugs, vol. 33, no. 3 , pp. 251-263, 2019. Available: https://doi.org/10.1007/s40263-019-00613-7.

[4] J. Cummings, "New approaches to symptomatic treatments for Alzheimer's disease," Molecular neurodegeneration, vol. 16, no. 1, pp. 1-13, 2021. Available: https://doi.org/10.1186/s13024-021-00424-9.

[5] FDA, "FDA grants accelerated approval for Alzheimer's drug [media release]," n.d.. [Online] Available: https://www.fda.gov/ [Accessed 14th August 2021].

[6] J. Cummings, P. Aisen, C. Lemere, A. Atri, M. Sabbagh, and S. Salloway, "Aducanumab produced a clinically meaningful benefit in association with amyloid lowering," Alzheimer's Research \& Therapy, vol. 13, no. 
1

pp.

$1-3$

2021

Available:https://doi.org/10.1186/s13195-021-00838-z.

[7] L. K. Huang, S. P. Chao, and C. J. Hu, "Clinical trials of new drugs for Alzheimer disease," J Biomed Sci, vol. 27 , no. 1, p. 18, Jan 6 2020. Available: https://doi.org/10.1186/s12929-019-0609-7.

[8] K. Mullane and M. Williams, "Alzheimer's disease beyond amyloid: Can the repetitive failures of amyloidtargeted therapeutics inform future approaches to dementia drug discovery?," Biochem Pharmacol, vol. 177, p. 113945, Jul 2020. Available: https://doi.org/10.1016/j.bcp.2020.113945.

[9] A. Alzheimer, R. A. Stelzmann, H. N. Schnitzlein, and F. R. Murtagh, "An English translation of Alzheimer's 1907 paper," Uber eine eigenartige Erkankung der Hirnrinde"," Clinical anatomy (New York, NY), vol. 8, no. 6, pp. 429-431, 1995. Available: https://doi.org/10.1002/ca.980080612.

[10] R. E. Tanzi and L. Bertram, "Twenty years of the Alzheimer's disease amyloid hypothesis: a genetic perspective," Cell, vol. 120, no. 4, pp. 545-555, 2005. Available: https://doi.org/10.1016/j.cell.2005.02.008.

[11] G. G. Glenner and C. W. Wong, "Alzheimer's disease and Down's syndrome: sharing of a unique cerebrovascular amyloid fibril protein," Biochemical and biophysical research communications, vol. 122, no. 3, pp. 1131-1135, 1984. Available: https://doi.org/10.1016/0006-291x(84)91209-9.

[12] K. Beyreuther and C. L. Masters, "Amyloid Precursor Protein (APP) and BZA4 Amyloid in the Etiology of Alzheimer's Disease: Precursor-Product Relationships in the Derangement of Neuronal Function," Brain Pathology, vol. 1, no. 4, pp. 241-251, 1991. Available: https://doi.org/10.1111/j.1750-3639.1991.tb00667.x.

[13] J. Hardy and D. Allsop, "Amyloid deposition as the central event in the aetiology of Alzheimer's disease," Trends in pharmacological sciences, vol. 12, pp. 383-388, 1991.

[14] D. J. Selkoe, "The molecular pathology of Alzheimer's disease," Neuron, vol. 6, no. 4, pp. 487-498, 1991. Available: https://doi.org/10.1016/01656147(91)90609-v.

[15] G. G. Glenner and C. W. Wong, "Alzheimer's disease: initial report of the purification and characterization of a novel cerebrovascular amyloid protein," Biochemical and biophysical research communications, vol. 120, no. 3, pp. 885-890, 1984. Available: https://doi.org/10.1016/s0006-291x(84)80190$\underline{4}$.

[16] F. Panza, M. Lozupone, G. Logroscino, and B. P. Imbimbo, "A critical appraisal of amyloid- $\beta$-targeting therapies for Alzheimer disease," Nature Reviews Neurology, vol. 15, no. 2, pp. 73-88, 2019. Available: https://doi.org/10.1038/s41582-018-0116-6.

[17] F. Panza, M. Lozupone, D. Seripa, and B. P. Imbimbo, "Amyloid- $\beta$ immunotherapy for Alzheimer's disease: Is it now a long shot?," Annals of neurology, vol. 85, no. 3, pp. 303-315, 2019. Available: https://doi.org/10.1038/s41582-018-0116-6.

[18] M. A. DeTure and D. W. Dickson, "The neuropathological diagnosis of Alzheimer's disease," Molecular neurodegeneration, vol. 14, no. 1, pp. 1-18, 2019. Available: https://doi.org/10.1186/s13024-0190333-5.

[19] G.-f. Chen et al., "Amyloid beta: structure, biology and structure-based therapeutic development," Acta Pharmacologica Sinica, vol. 38, no. 9, pp. 1205-1235, 2017. Available: https://doi.org/10.1038/aps.2017.28.

[20] S. Oddo et al., "Triple-transgenic model of Alzheimer's disease with plaques and tangles: intracellular $A \beta$ and synaptic dysfunction," Neuron, vol. 39, no. 3, pp. 409-421, 2003. Available: https://doi.org/10.1016/s0896-6273(03)00434-3.

[21] C. Haass and D. J. Selkoe, "Soluble protein oligomers in neurodegeneration: lessons from the Alzheimer's amyloid $\beta$-peptide," Nature reviews Molecular cell biology, vol. 8, no. 2, pp. 101-112, 2007. Available: https://doi.org/10.1038/nrm2101.

[22] L. Pini et al., "Brain atrophy in Alzheimer's Disease and aging," Ageing research reviews, vol. 30, pp. 25-48, 2016.

Available:

https://doi.org/10.1016/j.arr.2016.01.002.

[23] M. Bobinski et al., "The histological validation of post mortem magnetic resonance imaging-determined hippocampal volume in Alzheimer's disease," Neuroscience, vol. 95, no. 3, pp. 721-725, 1999. Available: https://doi.org/10.1016/s0306-4522(99)00476$\underline{5}$.

[24] J. L. Whitwell et al., "Neuroimaging correlates of pathologically defined subtypes of Alzheimer's disease: a case-control study," The Lancet Neurology, vol. 11, no. 
10, pp. 868-877, 2012. Available: https://doi.org/10.1016/s1474-4422(12)70200-4.

[25] J. Mendiola-Precoma, L. Berumen, K. Padilla, and G. Garcia-Alcocer, "Therapies for prevention and treatment of Alzheimer's disease," BioMed research international, vol. 2016, 2016. Available: https://doi.org/10.1155/2016/2589276.

[26] S. Schilling, J.-U. Rahfeld, I. Lues, and C. A. Lemere, "Passive $A \beta$ immunotherapy: current achievements and future perspectives," Molecules, vol. 23, no. 5, p. 1068, 2018. Available: https://doi.org/10.3390/molecules23051068.

[27] G. Gallardo and D. M. Holtzman, "Antibody therapeutics targeting $A \beta$ and Tau," Cold Spring Harbor perspectives in medicine, vol. 7, no. 10, 2017. Available: https://doi.org/10.1101/cshperspect.a024331.

[28] J. W. Arndt et al., "Structural and kinetic basis for the selectivity of aducanumab for aggregated forms of amyloid- $\beta$," Scientific reports, vol. 8, no. 1, pp. 1-16, 2018. Available: https://doi.org/10.1038/s41598-018-24501-0.

[29] C. H. van Dyck, "Anti-amyloid- $\beta$ monoclonal antibodies for Alzheimer's disease: pitfalls and promise," Biological psychiatry, vol. 83, no. 4, pp. 311-319, 2018. Available:

https://doi.org/10.1016/j.biopsych.2017.08.010.

[30] FDA, "US prescribing information 2021." Biogen Inc. ADUHELM ${ }^{\mathrm{TM}}$ (aducanumab-avwa). [Online]. Available: https://www.accessdata.fda.gov/scripts/cder/daf/ [Accessed 14th August 2021]

[31] N. D. Prins and P. Scheltens, "Treating Alzheimer's disease with monoclonal antibodies: current status and outlook for the future," Alzheimer's research \& therapy, vol. 5, no. 6 , p. 56, 2013. Available: https://doi.org/10.1186/alzrt220.

[32] M. Lozupone et al., "Anti-amyloid- $\beta$ protein agents for the treatment of Alzheimer's disease: an update on emerging drugs," Expert Opinion on Emerging Drugs, vol. 25, $2020 . \quad$ Available: https://doi.org/10.1080/14728214.2020.1808621.

[33] R. J. Andrew, K. A. Kellett, G. Thinakaran, and N. M. Hooper, "A Greek tragedy: the growing complexity of Alzheimer amyloid precursor protein proteolysis," Journal of Biological Chemistry, vol. 291, no. 37, pp. 1923519244, 2016.

Available:
[34] C. P. Boix, I. Lopez-Font, I. Cuchillo-Ibañez, and J. Sáez-Valero, "Amyloid precursor protein glycosylation is altered in the brain of patients with Alzheimer's disease," Alzheimer's Research \& Therapy, vol. 12, no. 1, pp. 1-15, 2020. Available: https://doi.org/10.1186/s13195-02000664-9.

[35] S. De et al., "Different soluble aggregates of $A \beta 42$ can give rise to cellular toxicity through different mechanisms," Nature communications, vol. 10, no. 1, pp. 1-11, 2019. Available: https://doi.org/10.1038/s41467019-09477-3

[36] P. Kocis et al., "Elucidating the $A \beta 42$ antiaggregation mechanism of action of tramiprosate in Alzheimer's disease: integrating molecular analytical methods, pharmacokinetic and clinical data," CNS Drugs, vol. 31, no. 6, pp. 495-509, 2017. Available: https://doi.org/10.1007/s40263-017-0434-z.

[37] F. Liu and C.-X. Gong, "Tau exon 10 alternative splicing and tauopathies," Molecular neurodegeneration, vol. 3, no. 1, pp. 1-10, 2008. Available: https://doi.org/10.1186/1750-1326-3-8.

[38] C. Ballatore, V. M.-Y. Lee, and J. Q. Trojanowski, "Tau-mediated neurodegeneration in Alzheimer's disease and related disorders," Nature reviews neuroscience, vol. 8, no. 9, pp. 663-672, 2007. Available: https://doi.org/10.1038/nrn2194.

[39] F. Hernandez and J. Avila, "Tauopathies," Cellular and Molecular Life Sciences, vol. 64, no. 17, pp. 22192233, 2007. Available: https://doi.org/10.1007/s00018007-7220-x.

[40] M. Goedert, M. Spillantini, R. Jakes, D. Rutherford, and R. Crowther, "Multiple isoforms of human microtubule-associated protein tau: sequences and localization in neurofibrillary tangles of Alzheimer's disease," Neuron, vol. 3, no. 4, pp. 519-526, 1989. Available: https://doi.org/10.1016/0896-6273(89)902109

[41] M. Goedert and R. Jakes, "Expression of separate isoforms of human tau protein: correlation with the tau pattern in brain and effects on tubulin polymerization," The EMBO Journal, vol. 9, no. 13, pp. 4225-4230, 1990. Available: 2075.1990.tb07870.x.

https://doi.org/10.1002/j.1460

[42] I. D'Souza and G. D. Schellenberg, "Regulation of tau isoform expression and dementia," Biochimica et Biophysica Acta (BBA)-Molecular Basis of Disease, vol. 
1739, no. 2-3, pp. 104-115, 2005. Available: https://doi.org/10.1016/j.bbadis.2004.08.009.

[43] N. Sergeant, A. Delacourte, and L. Buée, "Tau protein as a differential biomarker of tauopathies," Biochimica et Biophysica Acta (BBA)-Molecular Basis of Disease, vol. 1739, no. 2-3, pp. 179-197, 2005. Available: https://doi.org/10.1016/j.bbadis.2004.06.020.

[44] M. Goedert and R. Jakes, "Mutations causing neurodegenerative tauopathies," Biochimica et Biophysica Acta (BBA)-Molecular Basis of Disease, vol. 1739, no. 2-3, pp. 240-250, 2005. Available: https://doi.org/10.1016/j.bbadis.2004.08.007.

[45] V. L. Villemagne et al., "Amyloid $\beta$ deposition, neurodegeneration, and cognitive decline in sporadic Alzheimer's disease: a prospective cohort study," The Lancet Neurology, vol. 12, no. 4, pp. 357-367, 2013. Available: https://doi.org/10.1016/s1474-4422(13)700449.

[46] J. Götz, L. M. Ittner, N. Schonrock, and R. Cappai, "An update on the toxicity of A $\beta$ in Alzheimer's disease," Neuropsychiatric disease and treatment, vol. 4, no. 6, p. 1033, 2008. Available: https://doi.org/10.2147/ndt.s3016.

[47] A. Akram et al., "Stereologic estimates of total spinophilin-immunoreactive spine number in area 9 and the CA1 field: relationship with the progression of Alzheimer's disease," Neurobiology of aging, vol. 29, no. 9, pp. 1296-1307, 2008. Available: https://doi.org/10.1016/j.neurobiolaging.2007.03.007.

[48] M. Audrain et al., "Alzheimer's disease-like APP processing in wild-type mice identifies synaptic defects as initial steps of disease progression," Molecular neurodegeneration, vol. 11, no. 1, pp. 1-17, 2016. Available: https://doi.org/10.1186/s13024-016-0070-y.

[49] C. L. Sutphen et al., "Longitudinal decreases in multiple cerebrospinal fluid biomarkers of neuronal injury in symptomatic late onset Alzheimer's disease," Alzheimer's \& Dementia, vol. 14, no. 7, pp. 869-879, 2018.

Available:

https://doi.org/10.1016/j.jalz.2018.01.012.

[50] E. McDade et al., "Longitudinal cognitive and biomarker changes in dominantly inherited Alzheimer disease," Neurology, vol. 91, no. 14, 2018. https://doi.org/10.3410/f.734019088.793552993.

[51] E. E. Congdon and E. M. Sigurdsson, "Tau-targeting therapies for Alzheimer disease," Nature Reviews
Neurology, vol. 14, no. 7, pp. 399-415, 2018. Available: https://doi.org/10.1038/s41582-018-0013-z.

[52] D. T. Jones et al., "Tau, amyloid, and cascading network failure across the Alzheimer's disease spectrum," Cortex, vol. 97, pp. 143-159, 2017. Available: https://doi.org/10.1016/j.cortex.2017.09.018.

[53] C.-C. Tan et al., "Efficacy and safety of donepezil, galantamine, rivastigmine, and memantine for the treatment of Alzheimer's disease: a systematic review and meta-analysis," Journal of Alzheimer's Disease, vol. 41, no. 2, pp. 615-631, 2014. Available: https://doi.org/10.3233/iad-132690.

[54] S. Gilman et al., "Clinical effects of $A \beta$ immunization (AN1792) in patients with $A D$ in an interrupted trial," Neurology, vol. 64, no. 9, pp. 1553-1562, 2005. Available: https://doi.org/10.1212/01.wnl.0000159740.16984.3c.

[55] Y. Dong, X. Li, J. Cheng, and L. Hou, "Drug development for Alzheimer's disease: microglia induced neuroinflammation as a target?," International Journal of molecular sciences, vol. 20, no. 3, p. 558, 2019. Available: https://doi.org/10.3390/ijms20030558.

[56] P. S. Aisen et al., "Tramiprosate in mild-to-moderate Alzheimer's disease-a randomized, double-blind, placebo-controlled, multi-centre study (the Alphase Study)," Archives of medical science: AMS, vol. 7, no. 1, p. 102, $2011 . \quad$ Available https://doi.org/10.5114/aoms.2011.20612.

[57] M. Tolar, S. Abushakra, J. A. Hey, A. Porsteinsson, and M. Sabbagh, "Aducanumab, gantenerumab, BAN2401, and ALZ-801-the first wave of amyloidtargeting drugs for Alzheimer's disease with potential for near term approval," Alzheimer's research \& therapy, vol. 12, no. 1, pp. 1-10, 2020. Available: https://doi.org/10.1186/s13195-020-00663-w.

[58] S. Salloway et al., "Two phase 3 trials of bapineuzumab in mild-to-moderate Alzheimer's disease," New England Journal of Medicine, vol. 370, no. 4, pp. 322-333, $2014 . \quad$ Available: https://doi.org/10.1056/nejmoa1304839.

[59] Clinical Trials, "ClinicalTrials.gov. A Study to Evaluate Safety and Tolerability of Aducanumab in Participants With Alzheimer's Disease Who Had Previously Participated in the Aducanumab Studies 221AD103, 221AD301, 221AD302 and 221AD205 2020," $2020 . \quad$ [Online]. Available: https://clinicaltrials.gov/ct2/show/NCT04241068?term=a 
ducanumab\&draw=2\&rank=2. [Accessed 14th August 2021].

[60] R. S. Doody et al., "Phase 3 trials of solanezumab for mild-to-moderate Alzheimer's disease," New England Journal of Medicine, vol. 370, no. 4, pp. 311-321, 2014. Available: https://doi.org/10.1056/nejmoa1312889.

[61] R. Vandenberghe et al., "Active $A \beta$ immunotherapy CAD106 in Alzheimer's disease: A phase 2b study," Alzheimer's \& Dementia: Translational Research \& Clinical Interventions, vol. 3, no. 1, pp. 10-22, 2017. Available: https://doi.org/10.1016/j.trci.2016.12.003.

[62] Novartis Pharmaceuticals, "A Study of CAD106 and CNP520 Versus Placebo in Participants at Risk for the Onset of Clinical Symptoms of Alzheimer's Disease (GS1)," ClinicalTrials.gov. [Online]. Available: https://clinicaltrials.gov/ct2/show/NCT02565511.

[Accessed 14th August 2021].

[63] J. L. Cummings et al., "ABBY: A phase 2 randomized trial of crenezumab in mild to moderate Alzheimer disease," Neurology, vol. 90, no. 21, pp. 1889-1897, 2018.

Available:

https://doi.org/10.1212/wnl.0000000000005550.

[64] S. Ostrowitzki et al., "A phase III randomized trial of gantenerumab in prodromal Alzheimer's disease," Alzheimer's research \& therapy, vol. 9, no. 1, pp. 1-15, 2017. Available: https://doi.org/10.1186/s13195-0170318-y.

[65] F. Panza et al., "The potential of solanezumab and gantenerumab to prevent Alzheimer's disease in people with inherited mutations that cause its early onset," Expert opinion on biological therapy, vol. 18, no. 1, pp. 25-35, 2018. Available: https://doi.org/10.1080/14712598.2018.1389885.

[66] V. Coric et al., "Targeting prodromal Alzheimer disease with avagacestat: a randomized clinical trial," JAMA neurology, vol. 72, no. 11, pp. 1324-1333, 2015. Available: https://doi.org/10.1001/jamaneurol.2015.0607.

[67] E. Muntimadugu, R. Dhommati, A. Jain, V. G. S. Challa, M. Shaheen, and W. Khan, "Intranasal delivery of nanoparticle encapsulated tarenflurbil: A potential brain targeting strategy for Alzheimer's disease," European Journal of pharmaceutical sciences, vol. 92, pp. 224-234, 2016.

Available:

https://doi.org/10.1016/i.ejps.2016.05.012.

[68] H. Steiner, A. Fukumori, S. Tagami, and M. Okochi, "Making the final cut: pathogenic amyloid- $\beta$ peptide generation by $\mathrm{Y}$-secretase," Cell Stress, vol. 2, no. 11, p. 292, 2018.2 Available:

https://doi.org/10.15698/cst2018.11.162.

[69] J. A. Dobrowolska Zakaria and R. J. Vassar, "A promising new $\mathrm{y}$-secretase modulator for Alzheimer's disease," Journal of Experimental Medicine, vol. 218, no. 4, $2021 . \quad$ Available: https://doi.org/10.1084/jem.20210077.

[70] M. F. Egan et al., "Randomized trial of verubecestat for prodromal Alzheimer's disease," New England Journal of Medicine, vol. 380, no. 15, pp. 1408-1420, 2019. Available: https://doi.org/10.1056/nejmoa1812840.

[71] T. Burki, "Alzheimer's disease research: the future of BACE inhibitors," The Lancet, vol. 391, no. 10139, p. 2486, 2018. Available: https://doi.org/10.1016/s01406736(18)31425-9.

[72] F. Panza et al., "BACE inhibitors in clinical development for the treatment of Alzheimer's disease," Expert review of neurotherapeutics, vol. 18, no. 11, pp. 847-857, 2018.2 Available: https://doi.org/10.1080/14737175.2018.1531706.

[73] S. Salloway et al., "A phase 2 randomized trial of ELND005, scyllo-inositol, in mild to moderate Alzheimer disease," Neurology, vol. 77, no. 13, pp. 1253-1262, 2011.

Available:

https://doi.org/10.1212/wnl.0b013e3182309fa5.

[74] V. L. Villemagne et al., "A randomized, exploratory molecular imaging study targeting amyloid $\beta$ with a novel 8-OH quinoline in Alzheimer's disease: The PBT2-204 IMAGINE study," Alzheimer's \& Dementia: Translational Research \& Clinical Interventions, vol. 3, no. 4, pp. 622635 , 2017. Available:

https://doi.org/10.1016/j.trci.2017.10.001.

[75] T. Wisniewski and F. Goñi, "Immunotherapeutic approaches for Alzheimer's disease," Neuron, vol. 85, no. 6, pp. 1162-1176, 2015. Available: https://doi.org/10.1016/i.neuron.2014.12.064.

[76] J. A. Nicoll, D. Wilkinson, C. Holmes, P. Steart, H. Markham, and R. O. Weller, "Neuropathology of human Alzheimer disease after immunization with amyloid- $\beta$ peptide: a case report," Nature Medicine, vol. 9, no. 4, pp. 448-452, 2003. Available: https://doi.org/10.1038/nm840.

[77] E. Masliah et al., "A $\beta$ vaccination effects on plaque pathology in the absence of encephalitis in Alzheimer disease," Neurology, vol. 64, no. 1, pp. 129-131, 2005. 
Available:

\section{https://doi.org/10.1212/01.wnl.0000148590.39911.df}

[78] A. Serrano-Pozo et al., "Beneficial effect of human anti-amyloid- $\beta$ active immunization on neurite morphology and tau pathology," Brain, vol. 133, no. 5, pp. 1312-1327 2010.

Available:

https://doi.org/10.1093/brain/awq056.

[79] L. Montoliu-Gaya and S. Villegas, "A [...]Immunotherapeutic strategies: a wide range of approaches for Alzheimer's disease treatment," Expert reviews in molecular medicine, vol. 18, 2016. Available: https://doi.org/10.1017/erm.2016.11.

[80] C. Van Dyck et al., "Vanutide Cridificar (ACC-001) and QS-21 Adjuvant in Individuals with Early Alzheimer's Disease: Amyloid Imaging Positron Emission Tomography and Safety Results from a Phase 2 Study," The journal of prevention of Alzheimer's disease, vol. 3, no. 2, pp. 75-84, 2016. Available: https://doi.org/10.2174/1567205012666150302154121.

[81] M. R. Farlow et al., "Long-term treatment with active $A \beta$ immunotherapy with CAD106 in mild Alzheimer's disease," Alzheimer's research \& therapy, vol. 7, no. 1, pp. $1-13,2015 . \quad$ Available: https://doi.org/10.1186/s13195-015-0108-3.

[82] Alzforum, "Umibecestat," n.d.. [Online]. Available: https://www.alzforum.org/therapeutics/umibecestat. [Accessed 14th August 2021].

[83] J. A. Pillai and J. L. Cummings, "Clinical trials in predementia stages of Alzheimer disease," Medical Clinics, vol. 97, no. 3, pp. 439-457, 2013. Available: https://doi.org/10.1016/j.mcna.2013.01.002.

[84] D. Schenk et al., "Immunization with amyloid- $\beta$ attenuates Alzheimer-disease-like pathology in the PDAPP mouse," Nature, vol. 400, no. 6740, pp. 173-177, 1999. Available: https://doi.org/10.1038/22124.

[85] R. Alves, M. Yang, M. Batista, and L. Ferreira, "Alzheimer's disease: is a vaccine possible?," Brazilian Journal of Medical and Biological Research, vol. 47, no. 6, pp. 438-444, 2014 . Available: https://doi.org/10.1590/1414-431x20143434.

[86] C. A. Lemere, "Immunotherapy for Alzheimer's disease: hoops and hurdles," Molecular neurodegeneration, vol. 8, no. 1, pp. 1-6, 2013. Available: https://doi.org/10.1186/1750-1326-8-36.
[87] N. D. Prins and P. Scheltens, "Treating Alzheimer's disease with monoclonal antibodies: current status and outlook for the future," Alzheimer's research \& therapy, vol. 5, no. 6, pp. 1-6, 2013. Available: https://doi.org/10.1186/alzrt220.

[88] P. Lewczuk et al., "Neurochemical diagnosis of Alzheimer's dementia by CSF A $\beta 42, A \beta 42 / A \beta 40$ ratio and total tau," Neurobiology of aging, vol. 25, no. 3, pp. 273281, 2004. Available: https://doi.org/10.1016/s01974580(03)00086-1.

[89] O. Hansson, S. Lehmann, M. Otto, H. Zetterberg, and $P$. Lewczuk, "Advantages and disadvantages of the use of the CSF Amyloid $\beta(A \beta) 42 / 40$ ratio in the diagnosis of Alzheimer's Disease," Alzheimer's research \& therapy, vol. 11, no. 1, pp. 1-15, 2019. Available: https://doi.org/10.1186/s13195-019-0485-0.

[90] O. Adolfsson et al., "An effector-reduced anti- $\beta$ amyloid $(A \beta)$ antibody with unique $a \beta$ binding properties promotes neuroprotection and glial engulfment of $A \beta, "$ Journal of Neuroscience, vol. 32, no. 28, pp. 9677-9689, 2012. Available: https://doi.org/10.1523/jneurosci.474211.2012

[91] J. Arndt et al., "Structural and kinetic basis for the selectivity of aducanumab for aggregated forms of amyloid- $\beta$," Sci Rep, vol. 8, no. 1, pp. 6412, 2018. Available: https://doi.org/10.1038/s41598-018-24501-0.

[92] S. Mukhopadhyay and D. Banerjee, "A Primer on the Evolution of Aducanumab: The First Antibody Approved for Treatment of Alzheimer's Disease," Journal of Alzheimer's Disease, pp. 1-16, 2021. Available: https://doi.org/10.3233/jad-215065.

[93] B. Bohrmann et al., "Gantenerumab: a novel human anti-A $\beta$ antibody demonstrates sustained cerebral amyloid- $\beta$ binding and elicits cell-mediated removal of human amyloid- $\beta, "$ Journal of Alzheimer's Disease, vol. 28, no. 1, pp. 49-69, 2012. Available: https://doi.org/10.3233/jad-2011-110977.

[94] J. J. Mo, J. y. Li, Z. Yang, Z. Liu, and J. S. Feng, "Efficacy and safety of anti-amyloid- $\beta$ immunotherapy for Alzheimer's disease: a systematic review and network meta-analysis," Annals of clinical and translational neurology, vol. 4, no. 12, pp. 931-942, 2017. Available: https://doi.org/10.1002/acn3.469.

[95] T. Yang et al., "Target engagement in an Alzheimer trial: Crenezumab lowers amyloid $\beta$ oligomers in cerebrospinal fluid," Annals of neurology, vol. 86, no. 2, 
pp.

215-224,

2019.

Available:

https://doi.org/10.1002/ana.25513.

[96] D. Abi-Saab, M. Andjelkovic, N. Pross, P. Delmar, N. Voyle, and N. Esau, "MRI findings in the open label extension of the Marguerite RoAD study in patients with mild Alzheimer's disease," J Prev Alz Dis, vol. 4, p. 339, 2017.

Available:

https://doi.org/10.1016/j.jalz.2018.06.2381.

[97] J. Cummings, G. Lee, A. Ritter, M. Sabbagh, and K. Zhong, "Alzheimer's disease drug development pipeline: 2019," Alzheimer's \& Dementia: Translational Research \& Clinical Interventions, vol. 5, pp. 272-293, 2019. Available: https://doi.org/10.1016/j.trci.2019.05.008.

[98] L. Montoliu-Gaya and S. Villegas, "AßImmunotherapeutic strategies: a wide range of approaches for Alzheimer's disease treatment," Expert Reviews in Molecular Medicine, vol. 18, 2016. Available: https://doi.org/10.1017/erm.2016.11.

[99] FDA, "Biogen Inc. ADUHELM ${ }^{\mathrm{TM}}$ (aducanumabavwa)," n.d.. [Online]. Available: https://www.accessdata.fda.gov/scripts/cder/daf/ [Accessed 14th August 2021].

[100] S. Dhillon, "Aducanumab: First Approval," Drugs, pp. 1-7, 2021. Available: https://doi.org/10.1007/s40265021-01569-z.

[101] L. Schneider, "A resurrection of aducanumab for Alzheimer's disease," The Lancet Neurology, vol. 19, no. 2, pp. 111-112, 2020. Available: https://doi.org/10.1016/s1474-4422(19)30480-6.

[102] R. Howard and K. Y. Liu, "Questions EMERGE as Biogen claims aducanumab turnaround," Nature Reviews Neurology, vol. 16, no. 2, pp. 63-64, 2020. Available: https://doi.org/10.1038/s41582-019-0295-9.

[103] K. Mullane and M. Williams, "Alzheimer's disease beyond amyloid: Can the repetitive failures of amyloidtargeted therapeutics inform future approaches to dementia drug discovery?," Biochemical pharmacology, vol. 177, p. 113945, 2020. Available: https://doi.org/10.1016/j.bcp.2020.113945.

[104] M. E. Kennedy et al., "The BACE1 inhibitor verubecestat (MK-8931) reduces CNS $\beta$-amyloid in animal models and in Alzheimer's disease patients," Science translational medicine, vol. 8, no. 363, 2016. Available: https://doi.org/10.1126/scitranslmed.aad9704.
[105] L. S. Honig et al., "Trial of solanezumab for mild dementia due to Alzheimer's disease," New England Journal of Medicine, vol. 378, no. 4, pp. 321-330, 2018. Available: https://doi.org/10.1056/neimoa1705971.

[106] D. Lowe, "The return of aducanumab," In The Pipeline, 2019. [Online]. Available: https://www.science.org/content/blog-post/returnaducanumab.

[107] J. C. Lee, S. J. Kim, S. Hong, and Y. Kim, "Diagnosis of Alzheimer's disease utilizing amyloid and tau as fluid biomarkers," Experimental \& molecular medicine, vol. 51, no. 5, pp. 1-10, 2019. Available: https://doi.org/10.1038/s12276-019-0250-2.

[108] C. R. Jack Jr et al., "NIA-AA research framework toward a biological definition of Alzheimer's disease," Alzheimer's \& Dementia, vol. 14, no. 4, pp. 535-562, 2018.

Available:

https://doi.org/10.1016/j.jalz.2018.03.004.

[109] E. Stomrud, O. Hansson, H. Zetterberg, K. Blennow, L. Minthon, and E. Londos, "Correlation of longitudinal cerebrospinal fluid biomarkers with cognitive decline in healthy older adults," Archives of neurology, vol. 67 , no. 2, pp. 217-223, 2010. Available: https://doi.org/10.1001/archneurol.2009.316.

[110] M. Brys et al., "Prediction and longitudinal study of CSF biomarkers in mild cognitive impairment," Neurobiology of aging, vol. 30, no. 5, pp. 682-690, 2009. Available:

https://doi.org/10.1016/j.neurobiolaging.2007.08.010.

[111] L. A. Beckett et al., "The Alzheimer's Disease Neuroimaging Initiative: annual change in biomarkers and clinical outcomes," Alzheimer's \& Dementia, vol. 6 , no. 3 , pp. 257-264, 2010. Available: https://doi.org/10.1016/j.jalz.2010.03.002.

[112] M. De Leon et al., "Longitudinal CSF and MRI biomarkers improve the diagnosis of mild cognitive impairment," Neurobiology of aging, vol. 27, no. 3, pp. 394-401, 2006.2 Available: https://doi.org/10.1016/j.neurobiolaging.2005.07.003.

[113] F. H. Bouwman et al., "Longitudinal changes of CSF biomarkers in memory clinic patients," Neurology, vol. 69 , no. 10, pp. 1006-1011, 2007. Available: https://doi.org/10.1212/01.wnl.0000271375.37131.04.

[114] L. S. Schneider et al., "Clinical trials and late-stage drug development for A Izheimer's disease: an appraisal from 1984 to 2014," Journal of internal medicine, vol. 275, 
no. 3, pp. 251-283, 2014. Available: https://doi.org/10.1111/joim.12191.

[115] R. A. Sperling et al., "Amyloid-related imaging abnormalities in amyloid-modifying therapeutic trials: recommendations from the Alzheimer's Association Research Roundtable Workgroup," Alzheimer's \& Dementia, vol. 7, no. 4, pp. 367-385, 2011. Available: https://doi.org/10.1016/j.jalz.2011.05.2351.

[116] S. B. Haeberlein et al., "Emerge and Engage topline results: Phase 3 studies of aducanumab in early Alzheimer's disease: Developments in clinical trials and cognitive assessment," Alzheimer's \& Dementia, vol. 16, p. e047259, $2020 . \quad$ Available: https://doi.org/10.1002/alz.047259.

[117] G. Klein et al., "Gantenerumab reduces amyloid- $\beta$ plaques in patients with prodromal to moderate Alzheimer's disease: a PET substudy interim analysis," Alzheimer's research \& therapy, vol. 11, no. 1, pp. 1-12, 2019. Available: https://doi.org/10.1186/s13195-0190559-z.

[118] T. Hashimoto et al., "Apolipoprotein E, especially apolipoprotein E4, increases the oligomerization of amyloid $\beta$ peptide," Journal of Neuroscience, vol. 32, no. 43 , pp. 15181-15192, 2012. Available: https://doi.org/10.1523/jneurosci.1542-12.2012.

[119] C. J. Swanson, Y. Zhang, S. Dhadda, J. Wang, A. Koyama, and J. Kaplow, "Clinical and biomarker updates from BAN2401 Study 201 in early AD," in Clinical Trials on Alzheimer's Disease Conference, 2018, pp. 24-27. Available: https://doi.org/10.1016/j.jalz.2019.08.004.

[120] R. C. Gaspar, S. A. Villarreal, N. Bowles, R. W. Hepler, J. G. Joyce, and P. J. Shughrue, "Oligomers of $\beta$ amyloid are sequestered into and seed new plaques in the brains of an AD mouse model," Experimental Neurology, vol. 223, no. 2, pp. 394-400, 2010. Available: https://doi.org/10.1016/i.expneurol.2009.09.001.

[121] D. Dominguez et al., "Phenotypic and biochemical analyses of BACE1-and BACE2-deficient mice," Journal of Biological Chemistry, vol. 280, no. 35, pp. 3079730806, 2005.2 Available: https://doi.org/10.1074/jbc.M505249200.
[122] M. Ohno et al., "BACE1 gene deletion prevents neuron loss and memory deficits in 5XFAD APP/PS1 transgenic mice," Neurobiology of Disease, vol. 26, no. 1, pp. 134-145, 2007. Available: https://doi.org/10.1074/jbc.m505249200.

[123] L. McConlogue et al., "Partial reduction of BACE1 has dramatic effects on Alzheimer plaque and synaptic pathology in APP transgenic mice," Journal of Biological Chemistry, vol. 282, no. 36, pp. 26326-26334, 2007. Available: https://doi.org/10.1074/jbc.m611687200.

[124] T. Jonsson et al., "A mutation in APP protects against Alzheimer's disease and age-related cognitive decline," Nature, vol. 488, no. 7409, pp. 96-99, 2012. Available: https://doi.org/10.1038/nature11283.

[125] J. A. Maloney et al., "Molecular mechanisms of Alzheimer disease protection by the A673T allele of amyloid precursor protein," Journal of Biological Chemistry, vol. 289, no. 45, pp. 30990-31000, 2014. Available: https://doi.org/10.1074/jbc.m114.589069.

[126] S. Gauthier et al., "Effect of tramiprosate in patients with mild-to-moderate Alzheimer's disease: exploratory analyses of the MRI sub-group of the Alphase study," JNHA-The Journal of Nutrition, Health, and Aging, vol. 13, no. 6, pp. 550-557, 2009. Available: https://doi.org/10.1007/s12603-009-0106-x.

[127] K. Parrish, J. N. Sarkaria, and W. F. Elmquist, "Improving drug delivery to primary and metastatic brain tumors: strategies to overcome the blood-brain barrier," Clinical Pharmacology \& Therapeutics, vol. 97, no. 4, pp. 336-346, 2015. Available: https://doi.org/10.1002/cpt.71.

[128] K.-X. Dou et al., "Comparative safety and effectiveness of cholinesterase inhibitors and memantine for Alzheimer's disease: a network meta-analysis of 41 randomized controlled trials," Alzheimer's research \& therapy, vol. 10, no. 1, pp. 1-10, 2018. Available: https://doi.org/10.1186/s13195-018-0457-9. 